
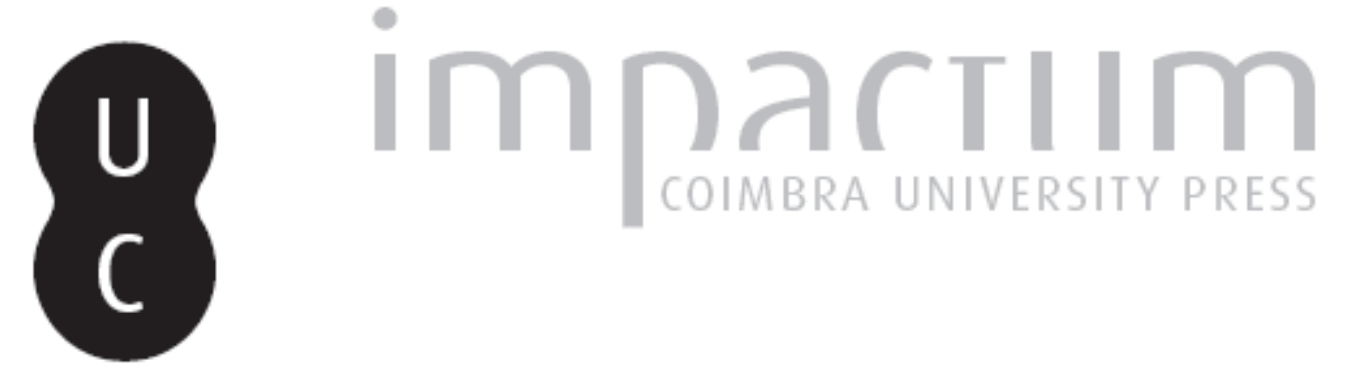

\title{
Los sacerdotes de rango local de la provincia romana de Lusitania
}

Autor(es): $\quad$ Delgado Delgado, José A.

Publicado por: Imprensa da Universidade de Coimbra

URL persistente:

URI:http://hdl.handle.net/10316.2/45374

DOI:

DOI:https://dx.doi.org/10.14195/1647-8657_39_4

Accessed : $\quad$ 26-Apr-2023 10:54:30

A navegação consulta e descarregamento dos títulos inseridos nas Bibliotecas Digitais UC Digitalis, UC Pombalina e UC Impactum, pressupõem a aceitação plena e sem reservas dos Termos e Condições de Uso destas Bibliotecas Digitais, disponíveis em https://digitalis.uc.pt/pt-pt/termos.

Conforme exposto nos referidos Termos e Condições de Uso, o descarregamento de títulos de acesso restrito requer uma licença válida de autorização devendo o utilizador aceder ao(s) documento(s) a partir de um endereço de IP da instituição detentora da supramencionada licença.

Ao utilizador é apenas permitido o descarregamento para uso pessoal, pelo que o emprego do(s) título(s) descarregado(s) para outro fim, designadamente comercial, carece de autorização do respetivo autor ou editor da obra.

Na medida em que todas as obras da UC Digitalis se encontram protegidas pelo Código do Direito de Autor e Direitos Conexos e demais legislação aplicável, toda a cópia, parcial ou total, deste documento, nos casos em que é legalmente admitida, deverá conter ou fazer-se acompanhar por este aviso.

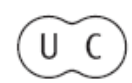


UNIVERSIDADE DE COIMBRA

FACULDADE DE LETRAS

\section{CONIMBRIGA}

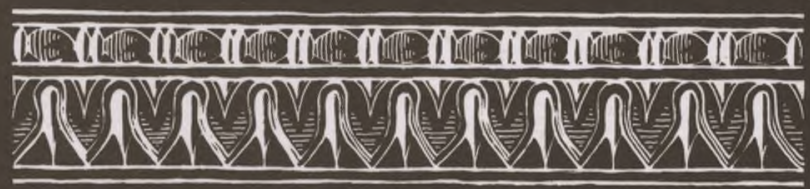

VOLUME XXXIX - 2000 


\section{José A. Delgado Delgado}

Area de Historia Antigua. Universidad de La Laguna

\section{LOS SACERDOTES DE RANGO LOCAL}

DE LA PROVINCIA ROMANA DE LUSITANIA

"Conimbriga" XXXIX (2000) p. 107-152

SUMMARY: It is the fundamental aim of this work to expose an analysis of all the local priests (so called "municipal priests") who are epigraphically recorded in the Roman province of Lusitania. The study has been divided into two basic parts: the first (chapters I-VI) is devoted to the analysis of the different priesthoods, that are arranged according to their features, and the second (chapter VII), to the alphabetic list of the known priests, containing the epigraphic and prosopographic bibliography.

RESUMO: El presente trabajo tiene como objetivo la catalogación y análisis de todos los sacerdotes de rango local (habitualmente llamados "sacerdotes municipales") que se atestiguan epigráficamente en la provincia romana de Lusitania $^{1}$. La investigación aborda de forma sistemática, por primera vez, el estudio de las distintas categorías de sacerdotes que se registran en las ciudades de la provincia, atendiendo en cada una de ellas tanto a los aspectos sociales y políticos como a los más propiamente religiosos, en la medida en que las inscripciones informan de ellos. A estos efectos el trabajo se ha estructurado en dos partes fundamentales: una (capítulos I-VI) consagrada al análisis de la evidencia documental y la otra (capítulo VII) al listado alfabético de los sacerdotes, con presentación y discusión de las bibliografías epigráfica y prosopográfica.

${ }^{1}$ Este trabajo se presenta como uno de los resultados del Proyecto de Investigación de Grupos Precompetitivos titulado "Sacerdocios de la Antigüedad", subvencionado por la Universidad de La Laguna (convocatoria de 1998).

Conimbriga, 39 (2000) 107-152 
(Página deixada propositadamente em branco) 


\section{LOS SACERDOTES DE RANGO LOCAL DE LA PROVINCIA ROMANA DE LUSITANIA}

\section{Sacerdotes de tradición romana}

Dentro de esta categoría de sacerdotes sólo se documentan en la provincia los pontifices; los cinco que se conocen se presentan en la tabla siguiente ${ }^{2}$ :

\begin{tabular}{|l|l|l|l|}
\hline Título & Nombre (cursus) [n. $\left.{ }^{\circ}\right]$ & Lugar & Datación \\
\hline ¿[pon]t.? perp. & $\begin{array}{l}{[- \text { Boc]chus (pr. Caesarum bis, fla- }} \\
\text { men perp., pr. fabr. V, tr. mil.) [32] }\end{array}$ & Salacia & Ia mitad s. I \\
\hline pont perpetuus & $\begin{array}{l}\text { L. Antestius Persicus Papiria } \\
\text { (IIviral.) [4] }\end{array}$ & Aug. Emerita & $\begin{array}{l}\text { mediados } \\
\text { s. Ill }\end{array}$ \\
\hline [pont?]if[ex?] & Pompeius [—]nus (Ilvir) [24] & Aug. Emerita & \\
\hline ¿pont(ifex)? & Acil[ia]nus (¿fla[m.] r. Pac. Iuli.?) [31] & Pax Iulia & \\
\hline pont[ifex] & $\begin{array}{l}{[-] \text { (fiam. Pacis Iuliae, flamen }} \\
{[\text { iperpetuus?]) [35] }}\end{array}$ & Pax Iulia & \\
\hline
\end{tabular}

Respecto a esta relación hay que tener en cuenta, como se refleja en la propia tabla, que sólo en dos de los cinco testimonios que aquí se recogen (n. ${ }^{\circ} 4$ y 35$)$ se lee con toda seguridad el título de ; en los otros tres la lectura del título es probable, pero no totalmente segura.

${ }^{2}$ Notas sobre la tabla: el número entre corchetes en la segunda columna remite al listado general final (capítulo VII); "Lugar", en la tercera columna, se refiere al lugar de procedencia del epígrafe. 


\section{Cronología de las inscripciones}

De las cinco inscripciones sólo se pueden datar dos, una en la primer mitad del siglo I y la otra hacia mediados del siglo III. Estos escasos datos sirven, al menos, para confirmar la presencia de este tipo de sacerdotes en la provincia en el lapso de tiempo comprendido entre ambas fechas.

\section{Origen y condición social de los pontífices}

Las inscripciones proceden de tres ciudades distintas, pertenecientes a dos de los conventus provinciales: dos de la capital provincial, Augusta Emerita (c. Emeritensis), dos de Pax Iulia (capital del c. Pacensis) y una de Salada (c. Pacensis). A pesar de que sólo en un epígrafe se indica la origo (Antestius Persicus, emerit ensis'), es muy probable que los pontífices fueran originarios de las ciudades de donde proceden sus inscripciones y en ellas desempeñaran el sacerdocio ${ }^{3}$.

De estas tres ciudades, dos poseyeron el estatuto jurídico de colonia (Augusta Emerita y Pax Iulia) y una el de municipium (Salada), lo que una vez más confirma que en provincias tanto las colonias como los municipios (y tal vez sólo estas dos categorías de comunidades ${ }^{5}$ ) podían contar con este tipo de sacerdotes.

Sobre la estructura onomástica, uno de los aspectos básicos para la determinación de la condición social, es poco lo que se puede decir, pues sólo la de uno de los pontífices se conoce completa: se trata del n. ${ }^{\circ}$ 4, que presenta los tria nomina y la tribu, indicadores ambos de ciudadanía romana. A pesar de ello, los cargos ejercidos por los cuatro restantes (ver apdo. siguiente) permiten deducir igualmente la posesión de la condición de cives romani y de uno de ellos, además, su pertenencia al ordo equester (n. ${ }^{\circ}$ 32). Estos indicadores pueden usarse, al mismo tiempo, para argumentar vínculos de estos individuos a las

3 Para algunos criterios orientativos que apoyan esta idea, ver el apartado origo de cada uno de los pontífices.

4 Sobre la condición jurídica de las ciudades se ha consultado fundamentalmente Galsterer 1971, Wiegels 1985 y Abascal y Espinosa 1989. Téngase en cuenta en adelante.

5 En la Bética todos los pontífices conocidos, que son nada menos que 33, proceden exclusivamente de colonias y municipios (Delgado Delgado 1998: 14). $C f$ Toutain 1907: 275 ss.

Conimbriga, 39 (2000) 107-152 
familias más importantes de sus respectivas comunidades, si bien hay que reconocer que no hay datos explícitos sobre ello ya que no han quedado huellas de sus relaciones familiares ${ }^{6}$.

\section{Cursus honorum}

Es interesante constatar que todos los pontífices desarrollaron carreras públicas en las que aparecen otros cargos aparte del sacerdocio. Los dos tipos básicos de cursus que presentan estos personajes se exponen en las siguientes tablas?

Tipo a): cursus local + cursus ecuestre

\begin{tabular}{|l|l|c|c|}
\hline Nombre [n. $\left.{ }^{\circ}\right]$ & Cargo & ap & $\mathrm{dp}$ \\
\hline$[-$ Boc]chus [32] & pr. Caesarum bis & $\mathrm{X}$ & \\
& flamen perp. & & $\mathrm{X}$ \\
& pr. fabr. V & & $\mathrm{X}$ \\
& tr. mil. & & $\mathrm{X}$ \\
\hline
\end{tabular}

Tipo b): cursus local

\begin{tabular}{|l|l|c|c|}
\hline Nombre [n. $\left.{ }^{\circ}\right]$ & Cargo & ap & dp \\
\hline L. Antestius Persicus [4] & II viral. & $X$ & \\
\hline Pompeius [-]nus [24] & Ilvir & $X$ & \\
\hline Acil[ia]nus [31] & flam. r. p. Pac. Iuli. & & $X$ \\
\hline$[-][35]$ & $\begin{array}{l}\text { flam. Pacis Iuliae } \\
\text { flamen [iperpetuus?] }\end{array}$ & & $\begin{array}{c}\text { X } \\
\end{array}$ \\
\hline
\end{tabular}

Con los datos proporcionados por tan sólo cinco inscripciones es ciertamente arriesgado pretender extraer conclusiones generales sobre

6 Sobre la cuestión de las relaciones familiares del n. ${ }^{\circ} 32$, [-Bocjchus, ver comentario en nota del listado final.

7 Abreviaturas de la tabla: ap = cargo ejercido antes del pontificado; $\mathrm{dp}=$ cargo ejercido después del pontificado.

Conimbriga, 39 (2000) 107-152 
la estructura de las carreras de los pontífices de Lusitania; aún así, es posible, al menos, apuntar ciertas tendencias.

Parece que debió ser poco frecuente el primer tipo de cursus, el mixto (cursus local + ecuestre), a juzgar por el único ejemplo conocido. Tal vez ello indica que muy pocos de los pontífices de la provincia solían acceder al ordo equester, limitándose generalmente a desarrollar carreras estrictamente locales ${ }^{8}$. En estas últimas es interesante destacar la presencia en dos casos de las más altas magistraturas civiles (duovirado) y también en otras dos de sacerdocios de culto imperial (flaminados).

El prestigio del pontificado parece indudable, pues es muy significativo que se desempeñara cronológicamente después de las magistraturas civiles (prefectura de los Césares y duovirado). Ahora bien, también es destacable que en las tres carreras en que aparecen flaminados, el pontificado siempre los precedió, lo que quizás se podría interpretar como un indicio del mayor prestigio que se otorgaba en las ciudades de la provincia al sacerdocio de culto imperial respecto al de los cultos tradicionales.

\section{El sacerdocio}

Los únicos datos sobre el sacerdocio propiamente dicho que ofrecen las pocas inscripciones pontificales conocidas se refieren exclusivamente a los títulos portados por estos sacerdotes ${ }^{9}$. Se constata así la existencia de dos títulos distintos, el de pontifex (3 casos) y el de pontifex perpetuus (2 casos). Este último es una prueba segura del carácter temporal del sacerdocio, muy probablemente limitado a un año de ejercicio. Como en los casos conocidos en otras provincias este título debía ser de carácter honorífico y probablemente comportaba la permanencia de la dignidad y quizás de los privilegios inherentes al cargo (ver apdo. II. 1.4).

8 La misma tendencia se ve mucho más claramente atestiguada en la Bética (Delgado Delgado 1998: 15 ss.).

9 Sobre las funciones cultuales de los pontífices locales puede verse Delgado Delgado 1998: 19 s.; id. 2000b, cap. 4.4.1 y textos n.os $44-45$. 


\section{Sacerdotes de tradición romana vinculados al culto imperial}

\section{Flámines}

La lista de flámines locales que a continuación se presenta cuenta con 22 entradas 1011 , lo que supone una notable actualización (no sólo por su número, sino también por nuevas lecturas) de la que presentó R. Etienne en 1958 en su clásica obra sobre el culto imperial en la Península Ibérica, con 12 entradas, que ha sido habitualmente la lista de referencia utilizada hasta el momento ${ }^{\mathrm{n}}$.

\begin{tabular}{|c|c|c|c|}
\hline Título & Nombre (cursus) $\left[\mathrm{n} .{ }^{\circ}\right]$ & Lugar & Datación \\
\hline $\begin{array}{l}\text { flamen Germ. Caesaris, } \\
\text { flamen Iuliae Aug. } \\
\text { in perpetu(u)m }\end{array}$ & Q. Iulius Q.f. Gal. Plotus (aed., Ilvir) [20] & Olisipo & $\begin{array}{l}\text { entre años } \\
14-19^{*}\end{array}$ \\
\hline [fl]amen Iuliae Augustae & $\begin{array}{l}\text { [C]n. Cornelius Cn.f. Pap. Severus } \\
\text { (aed., Ilvir, praefectus fabr.) [10] }\end{array}$ & Aug. Emerita & $\begin{array}{l}\text { entre años } \\
14-29 *\end{array}$ \\
\hline flamen Ti. Caesaris Aug. & M. Aurelius C.f. Gal. (Ilvir, praefec. fabr.) [8] & Pax Iulia & $\begin{array}{l}\text { época de } \\
\text { Tiberio * }\end{array}$ \\
\hline flam. Divi Aug. & L. Iulius Maelo Caudicus [18] & Armês & $\begin{array}{l}\text { época de } \\
\text { Tiberio o } \\
\text { Claudio * }\end{array}$ \\
\hline $\begin{array}{l}\text { ex d. d. [fl]amen Divi } \\
\text { August[i] [plerpet[uus] }\end{array}$ & [¿L.?] Iunius L.f. Gal. [P]hilo (Ilvir) [21] & Salacia & $\begin{array}{l}\text { época de } \\
\text { Tiberio o } \\
\text { Claudio * }\end{array}$ \\
\hline [flamen D]ivi August & ti[-]nius C.[f.?] Galba (Ilvir) [33] & Aug. Emerita & $\begin{array}{l}\text { época de } \\
\text { Tiberio o } \\
\text { Claudio * }\end{array}$ \\
\hline [fjlamen Divi Aug. & $\begin{array}{l}\text { [-] M.f. Ser. Modestus ([I]Ivir, praef fabr., } \\
\text { [flamen pjrovinc. Lusitan.) [34] }\end{array}$ & Aug. Emerita & $\begin{array}{l}\text { época de } \\
\text { Tiberio o } \\
\text { Claudio* }\end{array}$ \\
\hline
\end{tabular}

10 No se ha incluido en este cómputo el epígrafe del flamen L. Voconius Paullus, que aparece en el listado final en el apartado de "inscripciones de autenticidad dudosa" con la letra b).

11 Notas sobre la tabla. El listado se ha organizado cronológicamente. El asterisco $\left(^{*}\right)$ que aparece en algunas casillas de la columna "datación" indica que la fecha allí señalada es la del ejercicio del flaminado y no la del epígrafe, como en el resto de los casos donde no hay asterisco. 


\begin{tabular}{|c|c|c|c|}
\hline Título & Nombre (cursus) $\left[\mathrm{n} .^{\circ}\right]$ & Lugar & Datación \\
\hline $\begin{array}{l}\text { ¿flamen p. Divae } \\
\text { Aug.? } ?^{12}\end{array}$ & $\begin{array}{l}\text { Albinus Albui f. (flamen provinciae Lu- } \\
\text { sita[n.]) [2] }\end{array}$ & Aug. Emerita & c. año $42 *$ \\
\hline flamen col. Aug. I. [S.?] & $\begin{array}{l}\text { Aponius Capito (IIvir col. Aug. [-], praef. } \\
\text { fabrum, flamen provine. Lusitaniae Divi Aug. } \\
\text { Divae Aug.) [7] }\end{array}$ & Scallabis & año 48 \\
\hline flamen perp. & $\begin{array}{l}{[- \text { Boc }] \text { chus (pr. Caesarum bis, [pon?.]t. }} \\
\text { perp., pr. fabr. V, tr. mil.) [32] }\end{array}$ & Salacia & Ia mitad s. I \\
\hline fia. Divi Vesp. & P. Stai. G.f. Gal. Exoratus [28] & Lourel & $\begin{array}{l}\text { época de } \\
\text { Tito o Do- } \\
\text { mitiano * }\end{array}$ \\
\hline fia. Aug. & [_] ([H?]v.) [39] & Faião & $\begin{array}{l}i^{\mathrm{a}} \operatorname{mitad} \\
\text { s. I? }\end{array}$ \\
\hline flamen Divorum bis & $\begin{array}{l}\text { L. Porcius L.f. Gal. Himerus (Ilvir, praef. pro } \\
\text { Ilvir.) [25] }\end{array}$ & Salacia & \begin{tabular}{l|} 
s. I, poste- \\
terior a \\
Claudio \\
\end{tabular} \\
\hline [flam. Divoru]m Aug. & L. Cl[-]us M.f. Gal. Salvianus [9] & Pax Iulia & $\begin{array}{c}\text { posterior } \\
\text { a Claudio } \\
\end{array}$ \\
\hline flamen [DJivorum & [¿C. Iul?]ius C.f. [G]al. Pedo ([IIv]ir) [19] & Pax Iulia & $\begin{array}{l}\text { posterior } \\
\text { a Claudio } \\
\end{array}$ \\
\hline flam. col. & $\begin{array}{l}\text { C. Pompeius L.f. Pap. Priscus (Ilvir, flam, } \\
\text { pro. Lusit.) [23] }\end{array}$ & Aug. Emérita & $\begin{array}{l}\text { no ante- } \\
\text { rior a Ves- } \\
\text { pasiano } \\
\end{array}$ \\
\hline [fl] $\mathrm{am}[\mathrm{en}]$ & {$[-]$ (Ilvir [0]ssonob.) $[38]$} & Ossonoba & $\begin{array}{l}\text { ¿posterior } \\
\text { s. II? }\end{array}$ \\
\hline flam[en - ] & L. Co[melius -] (Ilvir) [11] & Salacia & \\
\hline flamen & Ummidius (Ilvir) [29] & Aug. Emerita & \\
\hline ¿fla[m.| r. Pac. Iuli.? & Acil[ia]nus (¿pont.?) [31] & Pax Iulia & \\
\hline $\begin{array}{l}\text { fiam. Pacis Iuliae, } \\
\text { flamen [¿perpetuus?] }\end{array}$ & {$[-]($ pont $[i f e x])[35]$} & Pax Iulia & \\
\hline $\begin{array}{l}\text { flamen [Div?/ } \\
\text { /August?] orum }\end{array}$ & $\mathrm{t}-][37]$ & Bobadela & \\
\hline
\end{tabular}

${ }^{12} \mathrm{La}$ lectura de este título es hipotética, por lo que su condición de flamen de rango local no es segura. Véase sobre ello el apartado "cursus" en la entrada correspondiente del listado final. 


\section{La cronología}

Es muy interesante constatar que de todas aquellas inscripciones que se han podido datar con una cierta seguridad, un total de 11, 10 pertenecen a la época del reinado de Tiberio (quizás algunas sean Claudianas) y 1 a la de Tito o Domiciano. Estas dataciones son bastante seguras, deducidas en su mayoría de los propios títulos que portan los flámines, y de ellas hay que concluir que bajo Tiberio el flaminado era un sacerdocio bien implantado en las ciudades de la provincia. La fuerte concentración de tantos testimonios flaminales durante el reinado del segundo de los emperadores romanos podría hacer pensar (a pesar de la falta de ejemplos explícitos), incluso, en una fecha de adopción anterior, en vida del propio Augusto, pues se explicaría así mejor su fuerte desarrollo con Tiberio ${ }^{13}$.

El resto de los documentos o bien no pueden ser datados o se les ha asignado fechas muy vagas e imprecisas (como ocurre con aquellos en los que la presencia de los títulos flame Divorum o flamen Divorum Augustorum asegura, al menos, que tales textos son posteriores a Claudio).

\section{Origen y condición social}

La diez ciudades de procedencia de las inscripciones flaminales se presentan a continuación ordenadas por conventus y con la indicación de su condición jurídica ${ }^{14}$. A pesar de que no se menciona la origo en los epígrafes hay que suponer que estas ciudades, con una sola excepción contrastada (n. ${ }^{\circ} 34$ ), se corresponden con las de origen de los flámines e igualmente con las del ejercicio del sacerdocio ${ }^{15}$.

Conventus Emeritensis: Augusta Emérita (col. en 25 a.e.; 6 flam.).

Conventus Pacensis: Ossonoba (?; 1 flam.); Pax Iulia (col. anterior 27 a.e.; 5 flam.); Salada (mun. de César; 4 flam.).

$13 C f$. Etienne 1958: 200 y 378 s.; Fishwick 1987: 156 s.

14 Que aparece abreviada de la siguiente forma: $c o l .=;$ mun. $=$ pium; mun. c. $R$. = municipium civium Romanoru; = condición jurídica desconocida.

15 Ver criterios en apartado de origo en las entradas correspondientes del listado final.

Conimbriga, 39 (2000) 107-152 
Conventus Scallabitanus: Armês (1 flam.) ${ }^{16}$; Bobadela (1 flam.); Faião (1 flam.); Lourel (1 flam.); Olisipo (mun.c.R. anterior 27 a.e.; 1 flam.); Scallabis \{col. anterior 27 a.e.; lflam.).

Uno de los aspectos más destacables de la relación expuesta es la especial concentración de testimonios en tres ciudades, Augusta Emérita, Pax Iulia y Salada, que en conjunto reúnen más del 68\% del total de los flámines de la provincia.

Las ciudades de origen cuya condición jurídica es conocida son todas colonias o municipios, con estatuto de privilegio antiguo, esto es, de época cesariana o augustea. Teniendo en cuenta este dato sería posible plantear la hipótesis de que en la provincia Lusitania la presencia del flaminado estuviese limitado sólo a esos dos tipos de comunidades (colonias y municipios). No hay que olvidar, sin embargo, que en la vecina provincia de la Bética se atestiguan sacerdotes de culto imperial en comunidades no privilegiadas ${ }^{17}$, por lo que es preferible otorgar un carácter provisional a tal hipótesis.

La estructura onomástica de los flámines, un buen criterio orientador de la condición social, presenta las siguientes características ${ }^{18}$ :

praenomen + nomen + filiación + tribu: 1

tria nomina: 1

tria nomina + filiación: 1 caso.

tria nomina + filiación + tribu: 9 casos.

La exposición no deja lugar a dudas sobre la condición de cives romani de todos los flámines, requisito social probablemente necesario para acceder al sacerdocio ${ }^{19}$. Un único caso parece contradecir esta regla general, el de Albinus, Albui f. (n. ${ }^{\circ}$ 2), cuya onomástica está al margen de los patrones romanos y sugiere un estatus peregrino y no ciudadano. Una explicación podría ser que quizás la ciudadanía no fuese una exigencia absolutamente rigurosa en los inicios de la organización del culto imperial y en provincias poco romanizadas como

16 Testimonio que habría que atribuir a Olisipo, pues procede del territorio del ager Olisiponensis.

17 Delgado Delgado 1998: 57; Delgado Delgado 2001: s.v. Anticaria y Epora. Cf Ladage 1971: 32 ss.

18 Sólo se han tenido en cuenta a estos efectos 13 flámines, aquJllos cuyos datos onomásticos se han conservado de forma suficientemente completa en las inscripciones.

$19 C f$. Toutain 1907: 164 s.; Etienne 1958: 223 s.; Delgado Delgado 1998: 57 y 65. 
Lusitania. Otra alternativa sería suponer que Albinus incluyó sólo parte de su nombre en la dedicación, pero de hecho poseía nomina y era ciudadano romano ${ }^{20}$.

A través de la epigrafía es prácticamente imposible conocer las relaciones familiares de estos sacerdotes, dado que apenas aporta datos en este sentido. No es posible, por tanto, reconstruir los grupos familiares y profundizar así en sus propios orígenes; al respecto lo único que autorizadamente se puede suponer (por la naturaleza de los cargos ejercidos) es su pertenencia a familias relevantes de sus respectivas comunidades.

\section{Las carreras de los flámines}

A través de los datos existentes sobre este aspecto se observa que el flaminado aparece integrado en un alto porcentaje de los casos en carreras públicas más o menos complejas, es decir, se muestra muy vinculado al ejercicio de otros cargos públicos, tanto de igual como de superior rango. Un total de 18 de los 22 flámines conocidos se encuentran en esta situación, lo que supone casi un $82 \%$ de la evidencia disponible $^{21}$. Hay que aclarar, sin embargo, que esto no autoriza la opinión de que el ejercicio de magistraturas locales era un requisito imprescindible para el acceso al sacerdocio, como han afirmado un buen número de investigadores ${ }^{22}$. No sólo hay que considerar el hecho de que se conocen algunas carreras en las que todos los cargos presentes se ejercieron con posterioridad al flaminado (vid. infra), sino también el de que hay individuos en cuyos cursus sólo se atestigua el flaminado. El ejemplo más contundente de este último tipo es el de P. Staius Exoratus (n. ${ }^{\circ} 28$ ), del que se puede estar prácticamente seguro

20 Ambas hipótesis fueron propuestas originalmente por Krascheninnikoff 1894 : 176 s., y aparecen recogidas y desarrolladas con paralelos epigráficos por Edmondson 1997: 99 ss.

21 Este porcentaje podría ser incluso más elevado, si tenemos en cuenta que algunas de las inscripciones están parcialmente dañadas (n..$^{\circ} 9$ y 37 ) y puede que sólo tengamos el registro de una parte del cursus.

22 Beurlier 1891: 178; Jullian 1896: 1186; Etienne 1958: 236; Rodríguez Neila 1981: 97; Curchin 1990: 43. Contra: Toutain 1907: 158 ss.; Delgado Delgado 1998: 65 (n. 1), 95 y $141 \mathrm{~s}$.

Conimbriga, 39 (2000) 107-152 
de que el único cargo público que ejerció a lo largo de su vida fue el de flamen Divi Vespasiani, porque es el único honor que aparece en su epígrafe funerario (murió a los 34 años).

Atendiendo al rango de los cargos ejercidos, se distinguen 4 tipos básicos de cursus desarrollados por los flámines ${ }^{23}$ :

$$
\text { tipo a) cursus local }+ \text { cursus ecuestre }+ \text { flaminado provincial }
$$

\begin{tabular}{|l|l|l|l|l|}
\hline Nombre [n. $\left.{ }^{\circ}\right]$ & Lugar & Cargo & af & df \\
\hline$[-]$ Modestus [34] & Emerita & $\begin{array}{l}\text { Ilvir } \\
\text { praef. fabr. } \\
\text { flamen provine. Lusitan. }\end{array}$ & & $\begin{array}{c}\text { X } \\
\text { X }\end{array}$ \\
\hline Aponius Capito [7] & Scallabis & $\begin{array}{l}\text { Ilvir col. Aug. } \\
\text { praef. fabrum } \\
\text { flamen provine. Lusitaniae } \\
\text { Divi Aug. Divae Aug. }\end{array}$ & X & \\
& & & X \\
\hline
\end{tabular}

tipo b) cursus local + flaminado provincial

\begin{tabular}{|l|l|l|l|l|}
\hline Nombre [n. ${ }^{\circ}$ ] & Lugar & Cargo & af & df \\
\hline Albinus, Albui f. [2] & Emerita & flamen provinciae Lusitan. & & X \\
\hline C. Pompeius Priscus [23] & Emerita & $\begin{array}{l}\text { Ilvir } \\
\text { flam. pro. Lusit. }\end{array}$ & & $\begin{array}{c}\text { X } \\
\text { X }\end{array}$ \\
\hline
\end{tabular}

23 Téngase en cuenta que para el orden cronológico de los cargos he partido del supuesto de que todos los cursus se presentan en orden directo. Tal supuesto lo fundamento en el hecho de que todos aquellos cursus cuyo orden se puede determinar con certeza o mucha probabilidad $\left(n .^{\circ} 7,10,20,23,32,34\right)$ se presentan en orden directo. Abreviaturas de las tablas: af = cargo ejercido antes del flaminado; $\mathrm{df}=$ cargo ejercido después del flaminado.

Conimbriga, 39 (2000) 107-152 
tipo c) cursus local + cursus ecuestre

\begin{tabular}{|l|l|l|l|l|}
\hline Nombre [n. $\left.{ }^{\circ}\right]$ & Lugar & Cargo & af & df \\
\hline Cn. Cornelius Severus [10] & Emerita & $\begin{array}{l}\text { aed. } \\
\text { llvir } \\
\text { praefectus fabr. }\end{array}$ & $\begin{array}{c}\mathbf{x} \\
\mathbf{x}\end{array}$ & $\mathbf{x}$ \\
\hline$[-$ Boc]chus [32] & Salacia & $\begin{array}{l}\text { pr. Caesarum bis } \\
\text { [pon]t. perp. } \\
\text { pr. fabr. V } \\
\text { tr. mil. }\end{array}$ & $\mathbf{x}$ & $\mathbf{x}$ \\
\hline M. Aurelius [8] & Pax Iulia & $\begin{array}{l}\text { Ilvir } \\
\text { praefec. fabr. }\end{array}$ & $\mathbf{x}$ \\
& & $\mathbf{x}$ & $\mathbf{x}$ \\
\hline
\end{tabular}

tipo d) cursus local

\begin{tabular}{|c|c|c|c|c|}
\hline Nombre $\left[\mathrm{n} .^{\circ}\right]$ & Lugar & Cargo & af & $\mathrm{df}$ \\
\hline Q. Iulius Plotus [20] & Olisipo & $\begin{array}{l}\text { aed. } \\
\text { Ilvir }\end{array}$ & $\begin{array}{l}\mathbf{x} \\
\mathbf{x}\end{array}$ & \\
\hline [L.?] Iunius Philo [21] & Salacia & Ilvir & $\mathbf{x}$ & \\
\hline [-]nius Galba [33] & Emerita & Ilvir & $\mathbf{x}$ & \\
\hline$[-][39]$ & Faião & {$[i \mathbf{n} ?] \mathbf{v}$} & $\mathbf{x}$ & \\
\hline L. Porcius Himerus [25] & Salacia & $\begin{array}{l}\text { Ilvir } \\
\text { praef. pro Ilvir }\end{array}$ & $\begin{array}{l}\mathbf{x} \\
\mathbf{x}\end{array}$ & \\
\hline [¿C. Iul?]ius Pedo [19] & Pax Iulia & {$[\mathrm{IIv}] \mathrm{ir}$} & $\mathbf{x}$ & \\
\hline$[-][38]$ & Ossonoba & Ilvir Ossonob. & & iX? \\
\hline L. Co[melius - $][11]$ & Salacia & Ilvir & $\mathbf{x}$ & \\
\hline Ummidius [29] & Emerita & Ilvir & ¿X? & \\
\hline Acilianus [31] & Pax Iulia & ¿pont.? & $\mathbf{x}$ & \\
\hline$[-][35]$ & Pax Iulia & pontifex & $\mathrm{x}$ & \\
\hline
\end{tabular}

Los tres primeros tipos de cursus son los que incluyen cargos de rango más elevado que el local, el flaminado provincial y del cursus ecuestre. El porcentaje de flámines que los desarrollaron es relativa- 
mente importante, casi un 39\% (7 casos), de lo que se puede inferir que la promoción de estos sacerdotes más allá de los puestos meramente locales no era un hecho excepcional24. Ahora bien, hay también que indicar que el único cargo ecuestre ejercido en la práctica totalidad de los casos fue el de más bajo rango, el de praefectus fabrum. Sólo [-Bocjchus (n. ${ }^{\circ}$ 32) escaló por encima de este peldaño en la jerarquía ecuestre, llegando a obtener el rango de tribuno militar. En otros casos el marco de los honores estrictamente locales se superó a través del ejercicio del flaminado provincial, sacerdocio que lograron obtener cuatro de los flámines locales.

El cursus estrictamente local es el que al parecer solía seguir la mayor parte de los flámines, a juzgar por los 11 ejemplos registrados (61 \% de la evidencia). En él predomina muy claramente la presencia de cargos de carácter civil y, dentro de ellos, la más alta magistratura, el duovirado (en 9 de las 11 carreras). Sólo en dos de los cursus aparece el pontificado, de lo que quizás debe deducirse que este sacerdocio no solía formar parte de las carreras de los flámines.

La posición del flaminado respecto a los otros cargos públicos en las carreras es una cuestión importante para determinar el prestigio y la importancia del sacerdocio. Por regla general el flaminado local se ejerció siempre con anterioridad a los cargos de rango superior al local: así ocurrió con respecto al flaminado provincial, con respecto al puesto de praefectus fabrum (en 4 de los 5 casos) y al tribunado militar.

Una posición bien distinta es la ocupada por el flaminado frente a los cargos locales. En las 14 carreras en las que están presentes el flaminado y el duovirado, la magistratura precedió cronológicamente en 12 ocasiones al sacerdocio; además el flaminado constituyó el colofón de 10 de las 11 carreras locales. Los datos expuestos permiten considerar el flaminado como el cargo probablemente más prestigioso de cuantos ofrecían los cursus públicos de las ciudades lusitanas, superando en ello incluso a la principal magistratura, el duovirado.

\section{El sacerdocio: títulos y cultos}

Uno de los aspectos peor documentados de los sacerdotes de ámbito local es precisamente el que atañe más directamente a sus acti-

\footnotetext{
${ }^{24}$ Es interesante en este aspecto el contraste con la situación la Bética, donde las carreras con cargos ecuestres son extremadamente raras (Delgado Delgado 1998: 65 ss.).
} 
vidades sacerdotales, a las prácticas cultuales ${ }^{25}$. Generalmente los únicos datos a través de los cuales es posible obtener información sobre estas cuestiones los proporcionan los títulos sacerdotales. Conviene, pues, presentar la relación de tales títulos (ordenados cronológicamente):

\begin{tabular}{|c|c|c|}
\hline Título $\left[\mathrm{n} .^{\circ}\right]$ & Fecha & Lugar \\
\hline flamen Germ(anici) Caesaris [20] & $14-19$ & Olisipo \\
\hline $\begin{array}{l}\text { flamen Iuliae Aug(ustae) in perpetu(u)m [20] } \\
\text { flamen Iuliae Augustae [10] }\end{array}$ & $\begin{array}{l}14-29 \\
14-29\end{array}$ & $\begin{array}{l}\text { Olisipo } \\
\text { Emerita }\end{array}$ \\
\hline [fl]amen Ti(berii) Caesaris Aug(usti) [8] & $\begin{array}{l}14-37 \\
\text { (reinado Tiberio) }\end{array}$ & Pax Iulia \\
\hline $\begin{array}{l}\text { flam(en) Divi Aug(usti) [18] } \\
\text { [flamen D]ivi Augusti [33] } \\
\text { [fjlamen Divi Augusti [34] } \\
\text { ex d.d. [fl]amen Divi August[i] [p]erpet[uus] [21] }\end{array}$ & $\begin{array}{l}\text { Tiberio o Claudio } \\
\text { Tiberio o Claudio } \\
\text { Tiberio o Claudio } \\
\text { Tiberio o Claudio }\end{array}$ & $\begin{array}{l}\text { Armês } \\
\text { Emérita } \\
\text { Emerita } \\
\text { Salacia }\end{array}$ \\
\hline ¿flamen p(erpetuus) Divae Aug(ustae)? [2] & c. año 42 & Emerita \\
\hline $\begin{array}{l}\text { flamen col(oniae) [7] } \\
\text { flam(en) col(oniae) [23] } \\
\text { flamen [29] } \\
\text { [fl]am[en] [38] } \\
\text { flam[en - ] [11] } \\
\text { flam(en) Pacis Iuliae [35] } \\
\text { ¿fla[m(en)] r(ei publicae) Pac(ensis) Iuli(ae)?[31] }\end{array}$ & $\begin{array}{l}\text { año } 48 \\
\text { no anterior } \\
\text { a Vespasiano } \\
? \\
9 \\
7 \\
7 \\
?\end{array}$ & $\begin{array}{l}\text { Scallabis } \\
\text { Emerita } \\
\text { Emerita } \\
\text { Ossonobe } \\
\text { Salacia } \\
\text { Pax Iulia } \\
\text { Pax Iulia }\end{array}$ \\
\hline $\begin{array}{l}\text { flamen perp(etuus) [32] } \\
\text { flamen [¿perpetuus?] [35] }\end{array}$ & $\begin{array}{l}\text { Ia mitad s. I } \\
7\end{array}$ & $\begin{array}{l}\text { Salacia } \\
\text { Pax Iulia }\end{array}$ \\
\hline fla(men) Divi Vesp(asiani) [28] & Tito o Domiciano & Lourel \\
\hline fla(men) Aug(¿usti/alis/orum?) [39] & 7 & Faião \\
\hline $\begin{array}{l}\text { flamen Divorum bis [25] } \\
\text { [flam(en) Divoru]m Aug(ustorum) [9] } \\
\text { flamen [D]ivorum [19] } \\
\text { flamen [iDiv? / ; August?]orum [37] }\end{array}$ & \multicolumn{2}{|c|}{$\begin{array}{l}\text { posterior a Claudio Salacia } \\
\text { posterior a Claudio Pax Iulia } \\
\text { posterior a Claudio Pax Iulia }\end{array}$} \\
\hline
\end{tabular}

25 Cf Delgado Delgado 1998: 155; id. 2000b, cap. 4.4.

Conimbriga, 39 (2000) 107-152 
La relación cronológica de los distintos tipos distintos de títulos registrados (10 en total) es especialmente ilustrativa de la evolución del culto imperial de rango local en las ciudades de la provincia. Los títulos más antiguos, de época de Tiberio y Claudio, claramente indican que las actividades cultuales de los flámines se vincularon al culto específico de ciertos miembros de la casa imperial, tanto vivos (Germánico y Julia Augusta) como divinizados (Augusto y posteriormente - bajo Claudio - quizás también su mujer, Julia). Al parecer, en las primeras décadas del nuevo régimen político el culto imperial tenía un marcado carácter personal.

Desde el año 48 hay constancia de la existencia del título simple de flamen, sin ninguna especificación de objeto de culto, lo que probablemente hay que interpretar como un indicio de una tendencia evolutiva del culto hacia formas más colectivas ya desde la época de Claudio. La presencia del título flamen Divorum y la extensión del título simple de flamen indican sin lugar a dudas la consolidación de esa tendencia. Esta evolución debió suponer un cambio en las competencias de los flámines, ahora relacionadas con la gestión de un culto colectivo que tendría que integrar tanto a los miembros vivos como a los deificados de la casa imperial ${ }^{26}$. A pesar de que esta parece que fue la regla general, títulos como el de flamen Divi Vespasiani hacen suponer que ciertos emperadores pudieron gozar aún del privilegio de un culto individual, personal.

Un título muy interesante es el de flamen luliae Augustae, documentado en Olisipo y Emerita, pues parece demostrar que al menos en esas ciudades no se había instituido aún (reinado de Tiberio) el flaminado femenino (por ello fueron flamines quienes se ocuparon del culto de una mujer de la casa imperial) ${ }^{27}$. En este sentido encuentro un paralelismo muy claro con el flaminado provincial (que tal vez ejerció cierta influencia sobre el local), donde he comprobado la precedencia del masculino (desde Tiberio) sobre el femenino (desde Vespasiano) ${ }^{28}$.

Aparte del objeto de culto, los títulos flaminales sólo aportan información sobre otro aspecto del sacerdocio, el de su duración. El título flamen perpetuus (con sus variantes) es totalmente explícito sobre el carácter temporal del cargo. La ya comentada integración del sacer-

$26 C f$ Etienne 1958: 234 s.; Delgado Delgado 1998: 62, 68 s y 70 ss.

27 En el mismo sentido ya Hirschfeld 1866: 48, n. 2.

28 Delgado Delgado 1999: 435, 441, 443 ss.

Conimbriga, 39 (2000) 107-152 
docio en las carreras de los notables locales y los datos al respecto de otras provincias son buenos argumentos para considerar el sacerdocio como un cargo anual. La "perpetuidad" sería un honor concedido a ciertos flámines una vez finalizado el ejercicio de sus funciones, que suponía quizás la permanencia de la dignidad sacerdotal ${ }^{29}$.

\section{Flaminicas}

El flaminado local femenino está representado por las inscripciones de 6 flaminicas ${ }^{30}$, que se presentan en la siguiente tabla.

\begin{tabular}{|l|l|l|l|}
\hline Título & Nombre (otros sacerdocios) [n. $\left.{ }^{\circ}\right]$ & Lugar & Datación \\
\hline flaminic[a] & [Gel]lia Vegeta [16] & Olisipo & $\begin{array}{l}\text { época de } \\
\text { Adriano }\end{array}$ \\
\hline $\begin{array}{l}\text { flamin. [mjunicipi sui } \\
\text { prim [a] et perpetua }\end{array}$ & $\begin{array}{l}\text { Domitia L.f. Proculina } \\
\text { (ff]laminica provin[c.] Lusitan.) [13] }\end{array}$ & Caesarobriga & $\begin{array}{l}\text { no anterior } \\
\text { a Vespasiano }\end{array}$ \\
\hline $\begin{array}{l}\text { flaminica col. } \\
\text { Emeritensis perpet. e } \\
\text { municipi. Salacien. }\end{array}$ & $\begin{array}{l}\text { Flavia L.f. Rufina (flaminica } \\
\text { provine. Lusitaniae) [14] }\end{array}$ & Salacia & $\begin{array}{l}\text { no anterior } \\
\text { a Vespasiano }\end{array}$ \\
\hline $\begin{array}{l}\text { flaminica Ebore(n)si } \\
\text { Laberia L.f. Galla (flaminica prov. }\end{array}$ & $\begin{array}{l}\text { Collippo / } \\
\text { iEbora? }\end{array}$ & $\begin{array}{l}\text { no anterior } \\
\text { a Vespasiano }\end{array}$ \\
\hline flaminica & Iulia Modesta [17] & Bobadela & Aug. Emérita \\
\hline flam. perp. & Val. Vini[c]iana [30] & & \\
\hline
\end{tabular}

\section{Cronología}

La única inscripción datada con cierta precisión permite asegurar, al menos, la existencia del flaminado femenino en época de Adriano. Si

29 Sobre la duración de los sacerdocios de rango local: Delgado Delgado 1998: 148 ss. (con bibliografía y discusión) y Delgado Delgado 2000: apdo. 3.3.

30 Como en el caso de los flámines, las inscripciones de autenticidad dudosa no se han tenido en cuenta ni en este cómputo ni en el estudio que se desarrolla a continuación. La discusión sobre los problemas de estos epígrafes se presenta en el listado general final (a) y c)). 
junto a esta fecha se tiene en cuenta los indicios ya comentados sobre la probable inexistencia de flaminicas en época de Tiberio, se podría hipotetizar que este sacerdocio femenino debió empezarse a adoptar en las ciudades de la provincia en unas fechas comprendidas entre la época de Claudio y la de los emperadores flavios.

En otros tres casos el título flaminica provinciae Lusitaniae proporciona un probable término post quem, Vespasiano, para fechar esos documentos ${ }^{31} 32$.

\section{Origen y condición social}

Las inscripciones flaminales proceden de 6 (i7?) ciudades distintas, repartidas entre los tres conventus de la provincia:

Conventus Emeritensis: Augusta Emerita \{col. en 25 a.e.); Caesarobriga \{mun. ${ }^{22}$ ).

Conventus Pacensis: Ebora ${ }^{33}$ \{mun. anterior 27 a.e.); Salada (mun. de CJsar).

Conventus Scallabitanus: Bobadela; Collippo \{mun.)| Olisipo \{mun.c.R. anterior 27 a.e.).

Como en el caso de los flámines se comprueba que las ciudades son todas de condición jurídica privilegiada (colonial o municipal), lo que quizás sea indicio de la necesidad de tal condición para la existencia de este sacerdocio.

A pesar de la falta de información expresa sobre la origo de estas mujeres hay datos (ver listado final) para creer que todas ellas debieron ser originarias de las ciudades de procedencia de sus epígrafes.

La onomástica de las flaminicas sigue fielmente el modelo tradicional romano, tanto en la estructura \{nomen + cognomen - con o sin filiación) como en la propia procedencia de los nombres (todos

31 Delgado Delgado 1999: 442 s.

32 No se conoce con seguridad la fecha de obtención del estatuto de municipium. La presencia de la tribu Quirina en la ciudad no es argumento decisivo, como se ha supuesto (Etienne 1958: 167), para fechar su municipalización en época flavia ( $c f$ Galsterer 1971: 68; Wiegels 1985: 74; Alfóldy 1987: 59).

33 Hay dudas sobre la autenticidad de esta inscripción (ver listado final), que registra a la misma flaminica que aparece en un epígrafe de Collippo. 
latinos), lo que sin duda es un claro indicador de la total integración de estas mujeres en los nuevos modelos impuestos por la romanización.

Las referencias epigráficas sobre los vínculos familiares de las flaminicas, aunque limitadas, son suficientes para confirmar la pertenencia de estas sacerdotisas a familias relevantes de sus ciudades ${ }^{34}$. Gellia Vegeta estaba casada con M. Gellius Rutilianus, magistrado (Ilvir) de Olisipo en época de Adriano; Domitia Proculina probablemente fue pariente de Domitia Attia, mujer de un magistrado local de Caesarobriga lulia Modesta fue esposa del flamen provincial Sex. Aponius Scaevus Flaccus ${ }^{35}$.

\section{Las "carreras" de las flaminicas}

Las flaminicas eran mujeres bien integradas en la vida pública de sus ciudades y también de la provincia, con una clara voluntad de participar activamente en estos ámbitos y obtener por ello un reconocimiento $^{36}$. Así lo demuestran las particulares carreras que desarrollaron algunas de ellas, vinculadas al ejercicio de varios sacerdocios (únicos cargos públicos, por otro lado, accesibles a las mujeres). Cabe recordar que tres de ellas llegaron a obtener el flaminado provincial (Domitia Proculina, Flavia Rufina, Laberia Galla), lo que quiere decir que su prestigio y fama traspasaron los IRmites de sus propias comunidades de origen. Una de éstas (Flavia Rufina), además, ejerció dos flaminados de rango local, en Emerita y Salada (flaminica coloniae) Emeritensis perpet(ua) et municipi(i) Salacien(sis)); otra (Domitia Proculina) tuvo el privilegio de ser la primera flamínicia de su municipio, concediéndosele posteriormente el honor de la perpetuidad.

\section{El sacerdocio}

Los aspectos concernientes a las prácticas cultuales de las flaminicas, es decir, los que tienen que ver específicamente con sus activi-

34 Cf Toutain 1907: 168 s.; Etienne 1958: 246; Mirón Pérez 1996: 162 s.;

Delgado Delgado 1998: 74 s.; id. 1999: 443 s.

35 Referencias documentales en listado final.

36 Cf. Mirón Pérez 1996: 211 ss.

Conimbriga, 39 (2000) 107-152 
dades sacerdotales, son en gran medida desconocidos por no haber quedado apenas datos de ellos en la epigrafía.

Se registran tres tipos distintos de títulos (con variantes) entre estas sacerdotisas, flaminica, flaminica perpetua, flaminica prima', ninguno, como se ve, incluye el objeto de culto. La uniformidad de los títulos y su comparación con los de los flámines sugiere que reflejan un momento en el que el culto imperial ha evolucionado hacia formas colectivas; las funciones cultuales de las flaminicas implicarían el culto conjunto de las mujeres de la casa imperial (tanto de las augustas como de las muertas y divinizadas). La adopción del flaminado femenino en las ciudades de la provincia, probablemente en una época más tardía que el masculino, habría significado un reparto de las obligaciones rituales entre flámines y flaminicas, adaptándose así a la práctica habitual en la gestión del culto imperial que se atestigua de forma general en las provincias del imperio ${ }^{37}$.

Los títulos y carreras de las flaminicas informan también sobre la temporalidad del sacerdocio: flaminica municipi sui prima et perpetua (n. $\left.{ }^{\circ} 13\right)$, flaminica coloniae Emeritensis perpetua et municipii Salaciensis (n. ${ }^{\circ}$ 14), flaminica perpetua (n. $\left.{ }^{\circ} 30\right)$. EI honor de la "perpetuidad", el adjetivo " $p r i m a$ ”, la sucesión de flaminados o el acceso al flaminado provincial son pruebas precisas de la duración limitada del sacerdocio, que probablemente fue la de un año ${ }^{38}$.

Finalmente cabe añadir que todo lo expuesto hasta ahora constituye un cúmulo de pruebas, en mi opinión concluyente, sobre la independencia del flaminado femenino de todo lazo conyugal y sobre la funcionalidad de tal sacerdocio ${ }^{39}$.

III. Sacerdotes de tradición oriental

Los sacerdotes de este tipo conocidos por la epigrafía pertenecen a los cultos de Cibeles (5) y Mitra (1).

37 Hirschfeld 1866: 48 s.; Herbst 1883: 11; Beurlier 1891: 174 s.; Geiger 1910:

3 ss.; Etienne 1958: 247; Ladage 1971: 42 ss.; Delgado Delgado 1998: passim.

38 Véase al respecto en el capítulo dedicado a los flámines.

39 Sobre esta cuestión ver ahora Delgado Delgado 1998: 143 s., con discusión y bibliografía. 


\section{Sacerdotes de Cibeles}

Los datos fundamentales sobre los cinco sacerdotes conocidos se exponen en la tabla que sigue:

\begin{tabular}{|l|l|l|l|l|}
\hline Título & Nombre [n. ${ }^{\circ}$ ] & Contexto ritual & Lugar & Datación \\
\hline arcigallus & $\begin{array}{l}\text { Publicius } \\
\text { Mysticus [27] }\end{array}$ & tauribolium & Aug. Emerita & fin s. II \\
\hline sacerdos & $\begin{array}{l}\text { Doccyricus } \\
\text { Valerianus [12] }\end{array}$ & tauribolium & Aug. Emerita & fin s. II \\
\hline sacerdos & L. Agrius [3] & crinobolium & Ossonoba & fin s. II o comienzo s. Ill \\
\hline sacer. & $\begin{array}{l}\text { L. Antist. } \\
\text { Avitus [5] }\end{array}$ & criobolium & Pax Iulia & $\begin{array}{l}\text { ¿mediados s. II?; ¿s. III?; } \\
\text { ¿s. IV? }\end{array}$ \\
\hline sacer. & $\begin{array}{l}\text { G. Antist. } \\
\text { Felicissimus [6] }\end{array}$ & criobolium & Pax Iulia & $\begin{array}{l}\text { ¿mediados s. II?; ¿s. III?; } \\
\text { ¿s. IV? }\end{array}$ \\
\hline
\end{tabular}

A pesar de ser relativamente escasos los testimonios de sacerdotes de Cibeles en Lusitania ${ }^{40}$, las tres inscripciones conocidas aportan valiosos detalles sobre las prácticas rituales, lo que ha de considerarse un hecho excepcional sobre todo si se compara con el habitual silencio que sobre estos aspectos guardan los epígrafes de los sacerdotes de tradición romana.

La inscripción de Emerita, fechada paleográficamente hacia finales del siglo II, muestra la colaboración de un sacerdos y un arcigallus (sic) en la celebración de un ritual taurobólico con ocasión del "natalicio" (sui natalicí) de Valeria Avita, la dedicante. La expresión sui natalici hace referencia explícita al concepto mistérico de "renacimiento a una vida nueva" que asume el fiel de la diosa frigia y experimenta físicamente a través del "bautismo" de sangre que recibe en el ritual $^{41}$.

40 Pero compárese con el caso de la vecina provincia de la Bética, donde sólo se conocen tres sacerdotes de Cibeles, uno de los cuales ni siquiera atestiguado de forma segura (Delgado Delgado 1998: 116 s.).

41 Turcan 1992: 58 y 64. Cf E. Hübner y Th. Mommsen (ad CIL II, 5260); García y Bellido 1967: 49. 
La onomástica del arcigallus, Publicius Mysticus, sugiere que se trata de un liberto de origen oriental, aunque hay que tener en cuenta que este título sacerdotal implicaba siempre, en función de los datos que se tienen, la posesión de la ciudadanía romana ${ }^{42}$. Por su parte, el nombre del sacerdos, Doccyricus Valerianus, hace pensar en un indígena romanizado ${ }^{43}$, lo que sería una muestra, si así fuera, del interés del culto entre los nativos de la provincia.

El epígrafe de Fax lulia, de datación discutida (¿s. III?; ¿s. IV?), reproduce el mismo "escenario mistérico" que el de Emerita; se trata también de la celebración de un "renacimiento" (mediante un criobolium, en este caso) que esta vez tiene como "beneficiarios" a una pareja formada por padre e hijo (duo Irinaei, pater et filius) y como oficiantes a dos sacerdotes que podrían ser hermanos o tal vez padre e hijo (L. Antist(ius) Avitus y G. Antist(ius) Felicissimus). De estos últimos es destacable su probable condición de ciudadanos romanos (en función de la presencia de tria nomina) y su propia relación parental, datos que hablan de la composición social del sacerdocio e informan de la existencia de ciertas "familias sacerdotales".

Una tercera inscripción, procedente de Ossonoba y parcialmente dañada, presenta al sacerdos L. Agrius [-] en el contexto ritual de un crinobolium, quizás en beneficio propio (no aparecen otros personajes).

Aparte de los sacerdotes propiamente dichos, se atestigua en una inscripción de Olisipo fechada en el año 108 (datación consular) el título-dignidad de cernophor(a), extraordinariamente raro en la epigrafía del culto de la diosa frigia ${ }^{44}$. Su portadora, Fl(avia) Thyche (n. $\left.{ }^{\circ} 15\right)$, una liberta de origen oriental, debía participar en el culto como portadora de ofrendas, a juzgar por la etimología del título ${ }^{45}$.

42 Latte 1960: 259 ss.; Thomas 1982: 1525 ss.; Turcan 1992: 54 ss.

43 Y no oriental de origen servil, como piensa Alvar (1993: 808 s.), quien sugiere además, en función del cognomen, una antigua relación de dependencia con Valeria Avita. Schillinger (1979: 50 s., n. ${ }^{\circ}$ 5) cree, por su parte, que probablemente era un servus publicus.

44 De hecho sólo se conoce una mujer más vinculada al culto de Cibeles con este título (CIL X, 1803).

45 La escasez de evidencia documental impide conocer las funciones precisas de ésta y otras categorías de personal cultual (por ej. apparatores, hymnologoi, tibicines o cymbalistriae) vinculado al culto frigio ( $c f$. Thomas 1982: $1532 \mathrm{~s}$.).

Conimbriga, 39 (2000) 107-152 


\section{Sacerdotes de Mitra}

El sacerdocio mitraico está solamente representado en la provincia por G. Accius Hedychrus (n. ${ }^{\circ} 1$ ), conocido a través de cuatro inscripciones de Emerita ${ }^{46}$. Esta escasez de testimonios ha de ponerse en relación con la muy limitada difusión que según los datos disponibles debió conocer este culto en Lusitania. Emerita es la única ciudad donde parece haber indicios suficientes parar creer en la existencia de una comunidad mitraica, que probablemente debió contar al menos con un mithraeum $^{41}$. Precisamente algunos de esos indicios están vinculados al personaje aquí tratado: estatua en mármol blanco de un dadophoros consagrada a Mitra (invicto sacrum) (inscr. n. ${ }^{\circ} 1$ ); estatua en mármol blanco de Mercurio sedente (dios del planeta ligado al primer grado de la iniciación mitraica) (inscr. n. ${ }^{\circ} 3$ ); estatua en mármol blanco de Oceanus consagrada a Mitra (invicto deo Mithrae sacr(um)) (inscr. n. ${ }^{\circ}$ 4). A estas tres estatuas, costeadas seguramente por el propio Hedychrus, hay que añadir una ara de mármol que rememora el nacimiento divino de Mitra (aram genesis invicti Mithrae), erigida por el frumentarius) leg(ionis) M. Val(erius) Secundus bajo la supervisión de Hedychrus (inscr. n. ${ }^{\circ}$ 2). Estos monumentos hablan por sí mismos de la posición preeminente de este liberto de origen oriental en la comunidad mitraica de la ciudad, situación que se ve confirmada igualmente a través de las dignidades obtenidas: ya en el año 155 aparece como pater, séptimo y último grado en la jerarquía iniciática del culto, y posteriormente como pater patrum, título supremo que le confiere el más alto rango posible en la religión del dios persa ${ }^{46} 4748$.

46 No se ha incluido al magis[t]er sodaliciu(m) Bracarorum de Pax Iulia, que tradicionalmente se ha relacionado con el culto de Mitra (así Vermaseren 1960: 35, n. ${ }^{\circ} 801$ bis; García y Bellido 1967: 34 s., n. ${ }^{\circ}$ 15; Alvar 1981: 53, n. ${ }^{\circ} 14$ - con dudas -; Bendala 1986: $397, \mathrm{n}^{\circ}$ 2), porque la revisión del texto llevada a cabo por Edmondson (1984) ha demostrado que no hay argumentos sólidos para seguir defendiendo la vinculación con dicho culto ni tampoco para considerar el título indicado propio de una asociación de carácter religioso. Clauss 1992 no incluye el título en sus listas.

47 García y Bellido 1967: 26 ss.; Bendala 1986: 395 ss.

48 Sobre la jerarquía iniciática y sus contenidos rituales ver Turcan 1992: 229 ss. 
IV. Sacerdotes de tradición indígena

Sólo una inscripción confirma la existencia de este tipo de sacerdotes en la provincia. Se trata de un documento en muy mal estado de conservación que procede de Cabeço dos Tiros (Penha Garcia, Idanhaa-Nova) (n. ${ }^{\circ}$ 26). El texto (según la lectura de Garda) está encabezado por el nombre de la diosa lusitana Trebaronna seguido de lo que podría ser el nombre de una mujer, Frota, Tancini/, el título sacerdos y el nombre del dedicante, G. Fron(tonius) Camal(us). Tanto el nombre de la divinidad como la filiación de la sacerdotisa y el nombre del dedicante remiten claramente al mundo indígena ${ }^{49}$.

\section{Sacerdotes de tradición desconocida}

Se incluye aquí una inscripción extremadamente fragmentada procedente de Sobreiral (Ninho do Açor) (n. $\left.{ }^{\circ} 36\right)$ en la que lo único que se lee es [sa]cerdo(s) h[os]tiam ded[ic]avit. J. d'Encamação ${ }^{50}$ sugiere que remite a un contexto indígena, tanto por la presencia del título sacerdos como por la de la palabra hostia (que se documenta en una inscrpción de una divinidad indígena - Reva Langanitaecus - de la misma zona), llegando a proponer que podría tratarse de una dedicación a divinidades locales como Arentius o Arentia, documentadas también en Ninho do Açor. En mi opinión estos argumentos no son suficientes para vincular el texto con el mundo indígena. Sacerdos fue un título que se aplicó a sacerdocios de muy diversa tradición (romana, indígena, oriental $^{51}$ y no hay ninguna razón objetiva en este caso para relacionarlo especialmente con la tradición indígena: en esta misma provincia hay cinco sacerdotes de tradición oriental por una única sacerdos de tradición indígena. La palabra hostia es un término de origen latino que designa de forma genérica a la víctima animal del sacrificio $^{52}$ y su simple empleo presupone ya al menos cierto grado de romanización.

49 Cf Abascal 1994: 313 s. y 522 s.

501989.

51 Delgado Delgado 1998: 22 ss., con ejemplos.

52 Marquardt 1885: 171 s.; Wissowa 1912: 412 ss.; Latte 1960: 279 s.; Benveniste 1983: $61 \mathrm{~s}$. 


\section{Consideraciones finales}

El número total de sacerdotes de rango local registrados en Lusitania asciende a 39, lo que significa que se conoce sólo una muy pequeña fracción de los fastos sacerdotales de las ciudades de la provincia. A pesar de ello, la dispersión espacial y temporal de los testimonios les asegura al menos una relativa representatividad $\mathrm{y}$, por tanto, también a las conclusiones históricas extraídas de su análisis.

Las ciudades de la provincia han proporcionado ejemplos de "sacerdotes de tradición romana" (I), "sacerdotes de tradición romana vinculados al culto imperial" (II), "sacerdotes de tradición oriental" (III) y "sacerdotes de tradición indígena" (IV), si bien el número de sacerdotes de cada una de las categorías no está en absoluto equilibrado. La categoría II es, con diferencia, la mejor representada, con 22 flámines y 6 flaminicas, lo que supone un $68.2 \%$ del total general; la categoría III, cuenta con 6 sacerdotes, un $14.6 \%$ del total; la categoría I presenta tan solo 5 ejemplos (y no todos completamente seguros), un $12.1 \%$ del total $\mathrm{y}$, finalmente, la categoría IV, con un único testimonio, un $2.4 \%$ del total.

La clara preeminencia de la categoría II sobre el resto ha de tener necesariamente como fundamento el mayor desarrollo del culto imperial en las ciudades de Lusitania en relación con el resto de los cultos, al menos desde el punto de vista de su organización. La comparación con la situación de la Bética, donde las diferencias entre las categorías I y II son mucho menos acusadas ${ }^{53}$, permite intuir que el menor grado de romanización de Lusitania ha influido en el mayor auge de los sacerdocios de culto imperial frente al resto de sacerdocios de tradición romana.

Con respecto a la categoría $I$, es especialmente destacable la ausencia de augures, dado que teóricamente habría que esperar su presencia al menos en municipios y colonias. En las otras dos provincias hispanas hay muy pocos documentos conocidos relativos a augures, concretamente sólo 6; este limitado número de testimonios en mi opinión no se debe a otra razón que el propio azar que preside habitualmente el hallazgo del documento epigráfico ${ }^{54}$.

53 Datos en Delgado Delgado 1998: passim y especialmente 137 ss.

54 Sobre los augures y el augurado en la Hispania romana, ver ahora Delgado Delgado 2000.

Conimbriga, 39 (2000) 107-152 
Finalmente, me parece de especial interés el epígrafe de la categoría IV, porque a pesar de su carácter singular confirma de forma explícita la existencia de un sacerdocio de tradición indígena en Lusitania, lo que ha de tenerse en cuenta en el contexto del debate historiográfico sobre la presencia o no de especialistas religiosos entre los celtas hispanos y, más concretamente, entre los lusitanos. A los datos aportados en favor de su existencia por F. Marco Simón o M. García Quintela $^{55}$ a luz de la comparación con otras áreas de tradición céltica de Europa, ha de sumarse ahora este testimonio, que posee el valor de ser un documento epigráfico (esto es, un documento rigurosamente histórico) generado en un ambiente indígena de la propia Lusitania en época imperial romana.

VIL Listado alfabético general de los sacerdotes de rango local de Lusitania

Las entradas se rigen por orden alfabético de nomina o, en su defecto, por el de cognomina. La información que se ofrece en cada entrada es la siguiente:

a) número de orden y nombre del sacerdote o sacerdotisa; b) lugar de procedencia de la inscripción. Se indica el nombre antiguo, si se conoce, y el nombre actual, provincia o freguesia, concelho y distrito, según proceda; c) bibliografía epigráfica ${ }^{56}$. La lectura preferida se presenta en primer lugar y el resto entre corchetes y ordenadas cronológicamente. Cuando hay más de una inscripción del mismo personaje cada una de ella se numera; cuando dos lecturas difieren sensiblemente se identifica cada una de ellas con las letras (a) y (b); d) bibliografía prosopográfica, ordenada cronológicamente; e) origo del personaje; f) título o cursus $\backslash$ g) contexto ritual, cuando se especifica en la inscripción; h) fecha.

55 1994: 372 ss. y 1999: 225 ss., respectivamente.

56 La revisión de la documentación epigráfica se ha realizado en el Fichero Central de CIL II, Universidad de Alcalá, y deseo agradecer aquí a su director, el Dr. Armin Stylow, y a su colaboradora, la Dra. Helena Gimeno, las facilidades que me han proporcionado para desarrollar esta labor. Las abreviaturas epigráficas utilizadas se desarrollan en el capítulo VIII.

Conimbriga, 39 (2000) 107-152 
Al final del listado se incluyen las entradas extraídas de inscripciones de autenticidad cuestionada, a cada una de las cuales se le ha asignado una letra minúscula para diferenciarlas de las anteriores.

\section{G. Accius Hedychrus}

Augusta Emérita (Mérida, Badajoz).

Ia. ERAE 21 [AE 1919, 87; HAE 2691]; 2a. ERAE 20 [AE 1905, 25; HAE 666; ILER 278]; 3a. ERAE 19 [HAE 1636]; 4a. ERAE 22 [AE 1905, 26; HAE 1637].

Vasconcelos 1913: 336 s.; García y Bellido 1949: n. ${ }^{\circ}$ 66, 108, 120; Vermaseren 1956: 272 ss. (n. ${ }^{\circ}$ 773-774, 778-781, 793); García y Bellido 1967: 27 s. (n. ${ }^{\circ}$ 1-4); Campbell 1968: 276; Le Roux 1972: 134 s. (n. ${ }^{\circ}$ 29); Alvar 1981: 51 s. (n. ${ }^{\circ}$ 1-4); Merkelbach 1984: 326; Bendala Galán 1986: 395 s. (n. $\left.{ }^{\circ} 1-4\right)$; Francisco Casado 1989: 33 ss., 51 ss.; Clauss 1992: 74; Alvar 1993: 791 s. y 802 s.; Klementa 1993: 74.

Origo: desconocida; el cognomen (ejemplo único en la epigrafía de Hispania) es de origen griego u oriental (Abascal 1994: 383, s.v.).

Título: pater $\left(\mathrm{I}^{\mathrm{a}}, 2^{\mathrm{a}}, 3^{\mathrm{a}}\right) ;$ p (ater) patrum (4a).

Fecha: año 155, era local $\left(2^{a}, 3^{a}\right)$.

2. Albinus Albui f.

Augusta Emérita (Mérida, Badajoz).

ERAE 50 + Trillmich 1993: 119, n. 16 (a); Edmondson 1997 (b).

Ciccotti 1891: 46; Krascheninnikoff 1894: 176-177; Kornemann 1901:

122; Toutain 1907: 133 y 139; Etienne 1958: 122-125 y 151; Deininger 1965:

29 y 131, n. 5; Fishwick 1970; Fishwick 1987: 157-158; Ramírez Sádaba

1993: 393; Francisco Martín 1996: 134; Delgado Delgado 1999: 445 s., n. ${ }^{\circ} 1$.

Origo: quizás de Emérita, ciudad donde se documentan tres Albini más (Abascal 1994: 264 s.).

Cursus: flamen p(erpetuus) Divae Aug(ustae), [flamen] provinciae Lusita[n(iae) $]^{51}$ o flamen D[ ivi Augusti et] Divae Aug( ustae) provinciae Lusitaniae] (b). ${ }^{57}$

57 Según la lectura propuesta por (a) el título del personaje sería flamen p(erpetuus) Divae Aug(ustae) provinciae Lusita[n(iae)]. Dado que la expresión $p$ (erpetuus) no se entiende en relación con un flaminado provincial, una posible explicación podría ser, como ya expuse en otro lugar (Delgado Delgado 1999: 442), que en realidad no se trate de un único título, sino de dos, pero que se han redactado de una forma que resulta confusa, quizás en un intento de abreviar el formulario. Albinus portaría, siguiendo esta hipótesis, un título local, flamen p(erpetuus) Divae Aug(ustae), y otro provincial, [flamen] provinciae Lusita[n(iae)]. 
Fecha: la presencia de la fórmula Divus Aug.-Diva Aug. sitúa la inscripción probablemente en los años inmediatamente posteriores al 42 , fecha de la consecratio de Livia.

\section{L. Agrius $[-]$}

Ossonoba (Faro).

IRCP 1 [HAE 2699; RAP 456].

García y Bellido 1967: 51 s. (n. ${ }^{\circ}$ 9); Duthoy 1969: 37 (n. ${ }^{\circ} 77$ );

Schillinger 1979: 56 (n. ${ }^{\circ}$ 25a); Encarnação 1981: 24 s.; Vermaseren 1986: 67

(n. ${ }^{\circ} 181$ ); Bendala Galán 1986: 391 (n. ${ }^{\circ}$ 9); Alvar 1993: 799 (n. 31) y 810.

Origo: ¿Ossonobal.

Título: sacerdos de Cibeles.

Contexto ritual: crinobo [l(ium) f(ecit)?].

Fecha: "seguramente do séc. III" (IRCP). Segunda mitad del s. II o comienzos s. III (Vermaseren).

4. L. Antestius Persicus Papiri<a $>$

Augusta Emérita (Mérida, Badajoz).

ERAE 145 [AE 1952, 117].

García y Bellido 1949: 294 s., n. ${ }^{\circ} 285$; Curchin 1990: n. ${ }^{\circ} 350$; Francisco Martín 1996: 133.

Origo: Emeriten(sis).

Cursus: Ilviral(is) ${ }_{y}$ pont(ifex) perpetuus.

Fecha: mediados del s. III, por la tipología del monumento (García y Bellido). García Iglesias (ERAE) sugiere que la paleografía permite una cronología anterior.

5. L. Antist(ius) Avitus

Pax Iulia (Beja).

IRCP 289 [HAE 2697; AE 1956, 255; RAP 457].

Vasconcelos 1935: 255 ss.; Lambrino 1953: 101 s.; García y Bellido 1967: 50 s. (n. ${ }^{\circ}$ 7); Duthoy 1969: 37 (n. ${ }^{\circ}$ 78) y 102; Schillinger 1970: 52 (n. ${ }^{\circ}$ 13-16); Dias 1981: 33 y 35; Bendala Galán 1986: 391 (n. ${ }^{\circ}$ 7); Vermaseren 1986: 68 (n. ${ }^{\circ} 182$ ); Alvar 1993: 795.

Origo: ¿Pax Iulial.

Título: sacer(dos) de Cibeles.

Contexto ritual: criobolium (junto con el n. ${ }^{\circ} 6$ ).

Fecha: mediados s. II, por criterios paleográficos (Lambrino, IRCP, RAP); mediados s. II o s. III, por criterios paleográficos (Dias; $c f$. Alvar); entre 319-390 (Duthoy, Schillinger); s. IV (Vermaseren). 
6. G. Antist(ius) Felicissimus

Pax Iulia (Beja).

IRCP 289 (ver n. ${ }^{\circ}$ ).

Origo: ¿Pax Iulial.

Título: sacer(dos) de Cibeles.

Contexto ritual: criobolium (junto con el n. ${ }^{\circ} 5$ ).

Fecha: ver n. ${ }^{\circ} 5$.

7. [- Aponius $^{58}[-$ Cjapito

Scallabis (Santarém).

RAP 546 (=HEp 4, 1994, 1084) [HAE 2640; AE 1966, 177; ILER 5540;

Cruz 1986: 116-117; Trillmich 1993: 120, n. 18].

Fishwick 1987: 157; Curchin 1990: n. ${ }^{\circ} 333$; Castillo 1991: 247; Demougin 1992: n. ${ }^{\circ}$ 463; Delgado Delgado 1999: 446 s., n. ${ }^{\circ} 2$.

Origo: probablemente Scallabis, pues se trata de una dedicación oficial ordenada por el senado local.

Cursus: Ilvir col(oniae) Aug(ustae) [-], praef(ectus) fabrum, flamen col(oniae) Aug(ustae) I(uliae) [S(callabis)?], flamen provinc(iae) Lusitaniae Divi Aug(usti) Divae Aug(ustae).

Fecha: año 48 (datación consular ${ }^{59}$ ).

8. M. Aurelius C. f. Gal.

Pax Iulia (Beja).

IRCP 236 [CIL II, 49; ILER 1557; RAP 529].

Herbst 1883: 6; Ciccotti 1891: 4; Fiske 1900: 106; Geiger 1913: 8; Etienne 1958: 199; Curchin 1990: n. ${ }^{\circ} 379$; Demougin 1992: n. ${ }^{\circ} 288$; Francisco Martín 1996: 124.

Origo: probablemente Pax Iulia, por la tribu (Wiegels 1985: 116).

Cursus: Ilvir, flamen Ti(berii) Caesaris Aug(usti), praefec(tus) fabr(um).

Fecha: época de Tiberio (14-37), por el título flaminal.

9. L. Cl[-]us M. f. Gal. Salvianus

Pax Iulia (Beja).

IRCP 238 [CIL II, 51; ILER 1583; RAP 530].

Ciccotti 1891: 4; Geiger 1913: 25; Etienne 1958: 200; Francisco Martín 1996: 125 .

58 El nomen podría ser también [Po]mponius, como lee Cruz.

59 Castillo 1991: 247 indica correctamente (ver Degrassi 1952: 14) que el praenomen del segundo cónsul no era G(aius), como aparece en el epígrafe, sino L(ucius)। la mejor solución para este problema, explica, sería pensar en un error del lapicida. 
Origo: probablemente Pax Iulia, por la tribu (ver n. $\left.{ }^{\circ} 8\right)$.

Cursus: [flam(en) Divorujm Aug(ustorum) [-] (cf n. $\left.{ }^{\circ} 19\right)$. Claudio.

Fecha: desconocida; el título flaminal es necesariamente posterior a

10. [C]n. Cornelius Cn.f. Pap. Severus

Augusta Emérita (Mérida, Badajoz).

Trillmich 1993: 120, n. ${ }^{\circ} 22$ [AE 1915, 95; ILER 1558; ERAE 95].

Etienne 1958: 199; Wiegels 1985: 78 s.; Curchin 1990: n. ${ }^{\circ} 332$; Fran-

cisco Martín 1996: 133; Delgado Delgado 1999: 442.

Origo: probablemente Emérita, cuya tribu es la Papiria (Wiegels).

Cursus: aed(ilis), Ilvir, [fljamen Iuliae Augustae, praefectus fabr(um).

Fecha: entre el año 14 y el 29, por el título flaminal.

11. L. Co[rnelius - $]^{60}$

Salada (Alcácer do Sal, Setúbal).

IRCP 188 [Faria 1984: n. ${ }^{\circ}$ 40; AE 1985, 499; RAP 527].

Curchin 1990: n. ${ }^{\circ}$ 390; Delgado Delgado 1999: 448, n. 25.

Origo: quizás Salada, de donde procede la inscripción.

Cursus: Ilvir [-], flam[en - ].

Fecha: desconocida.

12. Doccyricus ${ }^{61}$ Valerianus

Augusta Emérita (Mérida, Badajoz).

ERAE 16 [CIL II, 5260; ILS 4156; ILER 291].

Vasconcelos 1913: 331 s.; Lambrino 1954: 9 s.; García y Bellido 1967:

48 s., n. ${ }^{\circ}$ 4; Duthoy 1969: 37, n. ${ }^{\circ}$ 79; Schillinger 1979: 50 s., n. ${ }^{\circ}$ 5; Vermaseren

1986: 69, n. ${ }^{\circ} 186$; Bendala Galán 1986: 391, n. ${ }^{\circ}$ 4; Alvar 1993: 799 y 808 s.

Origo: desconocida.

Título: sacerdos de Cibeles.

Contexto ritual: tauribolium, junto con el arcigallus Publicius Mysticus (n. ${ }^{\circ} 27$ ).

Fecha: finales del s. II, por criterios paleográficos (CIL).

\section{Domitia L. f. Proculina}

Caesarobriga (Talavera de la Reina, Toledo).

60 La identificación que se ha sugerido (IRCP, RAP) entre este personaje, el flamen local [-Boc]chus $\left(\mathrm{n}^{\circ}{ }^{\circ}\right.$ 32) y el flamen provincial [-] Cornelius C.f. Bocchus no tiene ninguna justificación documental a tenor del estado actual del epígrafe, muy mutilado. Ver comentario en n. ${ }^{\circ} 32$.

61 Antropónimo de origen indígena (Abascal 1994: 345, s.v.). 
CIL II, 895 y p. 828 [Fita 1882: 258, n. ${ }^{\circ}$ 4; ILS 6895; ILER 1661].

Ciccotti 1891: 11 y 54; Kornemann 1901: 122; Toutain 1907: 142, n. 2; Etienne 1958: 166 s.; Deininger 1965: 131, n. 5; Wiegels 1985: 74; Alfóldy 1987: 59; Hoyo Calleja 1987: 115 s.; Mirón Pérez 1996: 329, n. ${ }^{\circ} 2$; Francisco Martín 1996: 136; Delgado Delgado 1999: 453 s., n. ${ }^{\circ} 13$.

Origo: probablemente de Caesarobriga, por el título flaminal de rango local.

Títulos: [f]laminica provin[c(iae)] Lusitan(iae) et flamin(ica) [m]unicipi sui prim[a] et perpetua.

Fecha: dado que se desconoce la fecha en que Caesarobriga obtuvo el estatuto municipal, no se puede ofrecer una datación precisa. Por criterios prosopográficos y paleográficos, así como por la fecha de introducción del flaminado provincial femenino, el texto no puede ser anterior a Vespasiano ${ }^{62}$.

\section{Flavia L. f. Rufina}

Salada (Alcácer do Sal, Setúbal).

IRCP 183 [CIL II, 32; ILS 6893; ILER 49; RAP 267],

Ciccotti 1891: 11 y 54; Kornemann 1901: 122; Toutain 1907: 142, n. 2; Etienne 1958: 166 s., 238; Deininger 1965: 131, n. 5; Hoyo Calleja 1987: 116 ss., 188; Ramírez Sádaba 1993: 393; Francisco Martín 1996: 125; Mirón Pérez 1996: 329, n. ${ }^{\circ}$; Delgado Delgado 1999: 454 s., n. ${ }^{\circ} 14$.

Origo: Emeritensis.

Títulos: flaminica provinc(iae) Lusitaniae, item col(oniae) Emeritensis perpet(ua) et municipi(i) Salacien(sis).

Fecha: no anterior a Vespasiano, por la presencia del flaminado provincial (ver n. $\left.{ }^{\circ} 13\right)$.

\section{Fl(avia) Tyche}

Olisipo (Lisboa).

CIL II, 179 [ILS 4099; Viera 1944: n. ${ }^{\circ}$ 25; ILER 376; RAP 460].

Ciccotti 1891: 22; Vasconcelos 1913: 328 ss.; García y Bellido 1967: 49 s., n. ${ }^{\circ}$ 5; Schilling 1979: 50, n. ${ }^{\circ}$ 1; Vermaseren 1986: 68, n. ${ }^{\circ}$ 184; Bendala Galán 1986: 391, n. ${ }^{\circ}$ 5; Alvar 1993: 799 y 809.

Origo: desconocida (porta cognomen de origen griego u oriental:

Abascal 1994: 536, s.v.).

Título: cernophor(a) del culto de Cibeles ${ }^{63}$.

Fecha: año 108 (datación consular).

62 Delgado Delgado 1999: $442 \mathrm{~s}$.

63 En el epígrafe aparecen dos personajes más, M. Iul(ius) Cass(ianus) y Cass(ia) Sev(era), a los que Vasconcelos (también Vieira y Schillinger 1979: 50, n. ${ }^{\circ} 2$ y 3) considera posibles sacerdotes. A falta de confirmación epigráfica de los títulos la propuesta ha de considerarse hipotética. 
16. [Gel]lia ${ }^{64}$ Vegeta

Olisipo (Lisboa).

Lambrino 1951: 39 ss., n. ${ }^{\circ} 2$ [CIL II, 5218/197; Vasconcelos 1927-29: 223 s., n. ${ }^{\circ}$ 26; Vieira 1944: 194 s., n. ${ }^{\circ}$ 83; AE 1953, 255; ILER 4453].

Ciccotti 1891: 10; Etienne 1958: 239; Hoyo Calleja 1987: 188 s.; Curchin 1990: n. ${ }^{\circ} 369$; Mirón Pérez 1996: 333, n. ${ }^{\circ}$ 52; Francisco Martín 1996: 129.

Origo: posiblemente de Olisipo, donde tanto ella como su marido, magistrado, ejercieron sus cargos.

Título: flaminic [a].

Fecha: época de Adriano, por criterios prosopográficos. Su marido, M. Gellius Rutilianus, fue IIvir del municipio en los años 121-122 (CIL II, 186 y 4992) $)^{65}$.

\section{Iulia Modesta}

Bobadela (Oliveira do Hospital, Coimbra).

Amaral 1982, n. ${ }^{\circ} 2$ [CIL II, 397; Vasconcelos 1913: 299; ILER 6080; Anacleto 1981:.$^{\circ}$ 1; RAP 548].

Ciccotti 1891: 10; Etienne 1958: 239; Hoyo Calleja 1987: 189 ss.; Francisco Martín 1996: 132; Mirón Pérez 1996: 333, n. ${ }^{\circ}$ 53; Delgado Delgado 1999: 436 s. y 447.

Origo: probablemente de la ciudad (de nombre desconocido) donde se asienta la moderna Bobadela, lugar de donde procede la inscripción y donde se documenta otro epígrafe de su marido, el flamen provincial Sex. Aponius Scaevus Flaccus (Delgado Delgado 1999: 447, n. ${ }^{\circ} 3$ ).

Título: flaminica.

Fecha: desconocida. La inscripción en la que aparece con su marido no debe ser anterior a la época de Vespasiano.

64 La lectura del nomen presenta problemas. Frente a la restitución de Lambrino (/Geljliae), que aquí se acepta, están las de Hübner (Caeliae) o Vasconcelos (Caeliae o Aeliae).

65 La afirmación de Curchin de que posiblemente fue también él flamen porque lo era su mujer, carece de fundamento. Ya se ha probado más allá de toda duda la independencia del flaminado municipal feminino respecto al masculino: Delgado Delgado 1998: 143 s. Francisco Martín sugiere un posible parentesco entre la flaminica y el flamen provincial C. Iul(ius) Vegetus, atestiguado en un epígrafe de S. Salvador de Aramenha (IRCP 617=CIL II, 160 y p. 809); no hay base documental para sustentar su hipótesis (sobre el flamen provincial: Delgado Delgado 1999: 450, n. ${ }^{\circ}$ ).

Conimbriga, 39 (2000) 107-152 
18. L. Iuliiis Maelo Caudicus

Armés (Terrugem, Sintra, Lisboa).

Ia. Ribeiro 1982/83: 173 [CILII, 260; ILER 1584; AE 1987, 478a; RAP

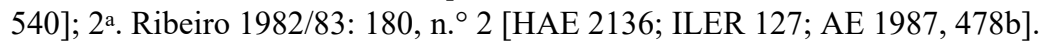

Ciccotti 1891: 3; Geiger 1913: 24; Etienne 1958: 199 s.; Mantas 1976: 157 ss.; Melchor Gil 1993/94: 338; Francisco Martín 1996: 129.

Origo: quizás de Olisipo, pues las inscripciones proceden del territorio del antiguo ager Olisiponensis. Los cognomina son antropónimos de origen indígena (Abascal 1994: 321 y 408, s.v.).

Título: flam(en) Divi Aug(usti).

Fecha: época de Tiberio o Claudio, por el título flaminal.

19. [¿C. Iul?]ius C. f. [G]al. Pedo

Fax lulia (Beja).

IRCP 239 [CIL II, 53; ILS 6897; ILER 1559; RAP 531].

Herbst 1883: 7, n. 7; Ciccotti 1891: 4; Geiger 1913: 21 y 25; Etienne 1958: 200; Dardaine-Pavis d'Escurac 1986: 299 (n. ${ }^{\circ}$ 5) y passim; Curchin 1990: n. ${ }^{\circ}$ 381; Francisco Martín 1996: 125.

Origo: Pax lulia, por la tribu y el carácter oficial de la dedicación. Cursus: [IIv]ir, flamen [DJivorum.

Fecha: época de los julio-claudios, por criterios paleográficos (IRCP); mediados s. II, sin especificar criterios (Francisco Martín). El título flamen Divorum implica una fecha necesariamente posterior a Claudio.

20. Q. Iulius Q. f. Gal. Plotus 66

Olisipo (Lisboa).

CIL II, 194 [ILS 6896; Vieira 1944: 142 s., n. ${ }^{\circ} 41$; ILER 5534].

Herbst 1883: 6 s.; Ciccotti 1891: 4; Fiske 1900: 106; Geiger 1913: 35; Etienne 1958: 199; Curchin 1990: n. ${ }^{\circ}$ 366; Francisco Martín 1996: 128.

Origo: posiblemente Olisipo, cuya tribu es la Galería (Wiegels 1985: 82 ss.), donde debió desarrollar su carrera.

Cursus: aed(ilis), Ilvir, flamen Germ(anici) Caesaris, flamen Iuliae Aug(ustae) in perpetu(u)m.

Fecha: entre el año 14 y el 19, por los títulos flaminales ${ }^{67}$.

21. [¿L.?] Iunius L. f. Gal. [P]hilo

Salada (Alcácer do Sal, Setúbal).

66 Único testimonio conocido de este cognomen en Hispania (Abascal 1994: 461, s.v.).

67 Julia recibió el título de Augusta tras la muerte de Augusto, en el año 14; Germánico murió en el año 19 (Cagnat 1914: 180 y 184). 
IRCP 186 [AE 1982, 461; RAP 523].

Curchin 392. 1985: 85).

Origo: probablemente Salada, cuya tribu es la Galería (Wiegels

Cursus: Ilvir, ex d(ecreto) d(ecurionum) [fljamen Divi August $[i]$ [p]erpet[uus].

Fecha: época de Tiberio o Claudio, por el título flaminal.

22. Laberia L. f. Galla

Ia. Collippo (São Sebastião do Freixo, Leiria).

Brandão 1972: 61-66, n. ${ }^{\circ} 4$ [CILII, 339; ILER 1774 y p. 834; RAP 547; Wesch-Klein 1993: 175-176].

Ciccotti 1891: 10 y 54; Kornemann 1901: 122; Toutain 1907: 148; Etienne 1958: 167, 239; Deininger 1965: 131, n. 5; Hoyo Calleja 1987: 118 s., 194; Francisco Martin 1996: 131; Mirón Pérez 1996: 329, n. 5; Delgado Delgado 1999: 455 s., n. ${ }^{\circ} 16$.

$2^{\text {a }}$. Ebora (Évora).

CIL II, 114 y p. 805 [ILER 5525; Brandão 1972: 61-66, n. ${ }^{\circ}$ 4; IRCP, p. 442; RAP, p. 567] $]^{68}$.

Origo: Ebora, donde ejerció el flaminado local, o quizás Collippo, cuyos decuriones le concedieron un homenaje postumo oficial.

Títulos: flaminica Ebore(n)si, flaminica prov(inciae) Lusitaniae (1); flaminica munic(ipii) Eborensis, flaminica provinciae Lusitaniae (2).

Fecha: desconocida (no anterior a Vespasiano, por el título provincial - ver $\left.n .^{\circ} 13\right)$.

23. C. Pompeius L. f. Pap. Priscus

Augusta Emérita (Mérida, Badajoz).

ERAE 112 [García y Bellido 1966: 131-132; HAE 2358; AE 1967, 187; ILER 6404; Wesch-Klein 1993: 176; Trillmich 1993: 117-119, n. 11].

Curchin 1990: n. ${ }^{\circ}$ 335; Ramírez Sádaba 1993: 393; Francisco Martín 1996: 133; Delgado Delgado 1999: 451 s., n. ${ }^{\circ} 9$.

Origo: probablemente de Augusta Emérita, por la tribu (que coincide con la de la colonia: Wiegels 1985: 110) y por ser esta la ciudad donde ejerció

68 Hübner (CIL II) tenía dudas sobre la autenticidad del epígrafe, quizás recreado a partir de la inscripción de Collippo. Encarnação (IRCP) considera que ciertamente se trata de una creación del humanista A. Resende forjada sobre el epígrafe de Collippo, opinión que acepta Garcia (RAP). Por su parte, autores como Komemann, Etienne, Deininger, Brandão, Hoyo Calleja, Wesch-Klein, Francisco Martín y Mirón Pérez no ponen en duda su autenticidad. 
sus cargos municipales; además el senado local le decretó un homenaje postumo oficial.

Cursus: flam(en) col(oniae), Ilvir, flam(en) pro(vinciae) Lusit(anie).

Fecha: no anterior a Vespasiano, por el título provincial ${ }^{69}$.

24. ¿L. [-] Pompe $<\mathrm{i}>$ us [-]nus?

Augusta Emérita (Mérida, Badajoz).

Mélida 1925: n. ${ }^{\circ} 907$ [ERAE 600].

Curchin 1990: n. $^{\circ} 336$.

Origo: desconocida.

Cursus: [-]IIvir [-ipont]if[ex? -].

Fecha: desconocida.

25. L. Porcius L. f. Gal. Himerus

Salada (Alcácer do Sal, Setúbal).

IRCP 187 [CIL II, 34; ILS 6894; ILER 1585; RAP 524].

Ciccotti 1891: 4; Geiger 1913: 25; Etienne 1958: 200; Curchin 1990: n. ${ }^{\circ}$ 391; Francisco Martín 1996: 125.

Origo: probablemente Salada, cuya tribu es la Galería (Wiegels 1985: 85) y cuya plebs lo homenajea ob merita.

Cursus: Ilvir, praef(ectus) pro Ilvir (o), flamen Divorum bis.

Fecha: s. I, por criterios prosopográficos, onomásticos y por tipología del monumento (IRCP). El título flaminal implica una fecha necesariamente posterior a Claudio.

26. ¿Prota, Tancini f.?

Cabeço dos Tiros (Penha Garcia, Idanha-a-Nova, Castelo Branco).

Ribeiro 1976: 136-138, n. 2 (=AE 1977, 381) (a); Garcia 1984: 71-72, n. ${ }^{\circ} 14$ (=RAP 195) (b).

Prósper 1994: 187; Crespo Ortíz de Zárate 1997: 36.

Comentario: texto de difícil lectura e interpretación (se trata de una ara de granito muy erosionada y partida por la mitad), en el que lo más claro y seguro parece la lectura del nombre de la divinidad que encabeza el epígrafe, Trebaronna, y el título [s]acer[dos].

69 Delgado Delgado 1999: $440 \mathrm{~s}$.

70 La lectura de Mélida, de quien depende ERAE, es imposible de verificar porque se desconoce el paradero del epígrafe. García Iglesias (ERAE) la considera insegura, sobre todo en lo que se refiere a la onomástica del personaje y al título que sigue al de Ilvir (a pesar de ello Curchin da el título de pontifex como lectura segura). 
Fecha: s. II (Ribeiro, en función de la fecha de otros testimonios del culto a Trebaronna); la misma datación ofrece Garcia, aunque sin especificar criterios.

27. Publicius Mysticus

Augusta Emérita (Mérida, Badajoz).

ERAE 16 [CIL II, 5260; ILS 4156; ILER 291].

Vasconcelos 1913: 331 s.; Lambrino 1954: 9 s.; García y Bellido 1967:

48 s., n. ${ }^{\circ}$; Duthoy 1969: 37, n. ${ }^{\circ}$ 79; Schillinger 1979: 50 s., n. ${ }^{\circ}$ 6; Vermaseren 1986: 69, n. ${ }^{\circ}$ 186; Bendala Galán 1986: 391, n. ${ }^{\circ}$ 4; Alvar 1993: 799 y 808 s.

Origo: desconocida; el cognomen (ejemplo único en la epigrafía de Hispania) es de origen griego u oriental (Abascal 1994: 435, s.v.)

Título: arcigallus (sic), de Cibeles.

Contexto ritual: tauribolium, junto con el sacerdos Doccyricus Valerianus $\left(\mathrm{n} .^{\circ} 12\right)$.

Fecha: finales del s. II, por criterios paleográficos (CIL).

28. P. Stai(us) G. f. Cal. Exoratus

Lourel (Sintra, Lisboa).

Ribeiro 1982/83: 227 ss. [HAE 1620; AE 1987,478d; HEp 2, 1990, 816; RAP 542].

Origo: desconocida.

Título: fla(men) Divi Vesp(asiani).

Fecha: probablemente época de Tito o Domiciano, por el título flaminal ${ }^{71}$.

29. Ummidius

Augusta Emérita (Mérida, Badajoz).

Curchin 1990: n. ${ }^{\circ} 338$ da la noticia de esta inscripción inédita del anfiteatro, consignando sólo los datos referidos a su gentilicio y cursus (cf HEp 4, 1994, 160).

Cursus: IIvir, flamen.

30. Val(eria) Vini[c]iana ${ }^{72}$

Augusta Emérita (Mérida, Badajoz).

CIL II, 494 y p. 696 [ERAE 113; ILER 5312].

Ciccotti 1891: 11; Etienne 1958: 239; Hoyo Calleja 1987: 195 ss.; Francisco Martín 1996: 135; Mirón Pérez 1996: 333, n. 55. 1879: 43).

71 Vespasiano fue divinizado en el año mismo de su muerte, el 79 (Desjardins

72 Único ejemplo conocido de este cognomen en Hispania (Abascal 1994: 546, s.v.).

Conimbriga, 39 (2000) 107-152 
Origo: probablemente Augusta Emérita, su liberto era emeritensis. Título: flam(inica) perp(etua).

Fecha: desconocida.

31. [-] Acil[ia]nus

Pax Iulia (Beja).

IRCP 343 ( $c f$. RAP, p. 563, ni Ib) + Viana 1952: 6 [=HAE 174=AE 1952, 242=ILER 5520].

Etienne 1958: 200; Wesch-Klein 1993: 175; Francisco Martín 1996: 125.

Origo: quizás Pax Iulia, por ser el lugar de procedencia del epígrafe y por el título flaminal (si estuviera bien leido).

Cursus: ¿pont(ifex), fla[m(en)] r(ei publicae) Pac(ensis) Iuli(ae)?73.

Fecha: desconocida.

32. [-Boc] chus ${ }^{74}$

Salada (Alcácer do Sal, Setúbal).

Vasconcelos 1895: passim [CIL II, 2479=5617 y p. 902; EE VIII, 4;

ILER 1546; IRCP 189; RAP 526].

PIR5 C 1333; Etienne 1958: 122 ss., 199 s.; Devijver 1976: 292, n. ${ }^{\circ} 228$; Devijver 1987: 1525; Menella 1989: 379 y 384; Curchin 1990: n. ${ }^{\circ} 389$; Demougin 1992: 423 ss., n. ${ }^{\circ}$ 512; Francisco Martín 1996: 127; Delgado Delgado 1999: 448, n. 25.

Origo: quizás Salada, de donde procede la inscripción.

73 El estado actual de la piedra impide cualquier restitución segura, pero en IRCP se acepta como posible la lectura de Viana (basada en un manuscrito de Caetano da Silva). Aunque obviamente esa lectura es imposible de confirmar, los elementos iconográficos grabados en el ara ("do lado direito, a meio, um prato (?) em relevo: apenas o bordo em círculo e a saliência central: do lado esquerdo, a pedra foi estragada (teria o jarro?)", según IRCP) podrían ser instrumentos sacerdotales (¿pátera y jarra de libaciones?); si ello fuera así la restitución de los títulos sacerdotales encontraría cierto apoyo.

74 La identificación de este personaje con el flamen provincial [-] Cornelius C.f Bocchus, como se ha pretendido (EE, IRCP, RAP, PIR, Etienne, Menella, Curchin, Demougin, Francisco Martín), es, en el estado actual de la documentación, muy discutible. En realidad, si se tiene en cuenta lo que realmente se puede leer con seguridad de las inscripciones (sobre todo en lo que respecta al c ursus), en mi opinión parece más probable que se trate de dos personajes distintos. Sobre la posible relación entre este personaje y el Cornelius Bocchus citado por Plinio como fuente para asuntos de Hispania (HN XXXVII, 127) y Lusitania (.HN XXXVII, 24, 97), así como con el Bocchus auctor citado por Solino $(1,97 ; 2,11 ; 2,18)$, nada se puede decir con seguridad (sobre estos problemas ver Delgado Delgado 1999: 447s s., n. ${ }^{\circ}$ ).

Conimbriga, 39 (2000) 107-152 
Cursus: pr(aefectus) Caesarum bis, [- ipon]t(ifex)? perp(etuus), flamen perp(etuus), [-] pr(aefectus) fabr(um) V?, tr(ibunus) mil(itum).

Fecha: por la presencia del título pr(aefectus) Caesarum bis se han propuestos las siguientes dataciones: Augusto o Tiberio (CIL II); Augusto-Tiberio o Vespasiano-Tito (Etienne); primera parte s. I (Devijver 1976, Menella); época julio-claudia (Demougin).

33. [-]nius C. [f.?] Galba

Augusta Emérita (Mérida, Badajoz).

ERAE 103 + Trillmich 1993: 122, n. 23 y fig. 5 .

Curchin 1990: n. $^{\circ} 345$.

Origo: desconocida.

Cursus: [-] Ilvir, [-flamen D]ivi Augusti.

Título: época de Tiberio o Claudio, si el título flaminal estuviese bien leído.

34. [-] M. f. Ser. Modestus

Augusta Emérita (Mérida, Badajoz).

Trillmich 1993: 119, n. 13 [ERAE 108].

Curchin 1990: n. ${ }^{\circ}$ 348; Francisco Martín 1996: 133; Delgado Delgado 1999: 452, n. ${ }^{\circ} 10$.

Origo: desconocida (no debió ser de Augusta Emérita, pues la tribu de la colonia era la Papiria).

Cursus: [f]lamen Divi Aug(usti), [l]Ivir, praef(ectus) fabr(um), [flamen p]rovinc(iae) Lusitan(iae).

Fecha: el flaminado local se ejerció en época de Tiberio o Claudio, a juzgar por el título.

35. $\mathrm{I}-\mathrm{]}$

Pax Iulia (Beja).

IRCP 242 [CIL II, 55; Curchin 1982: 106 s., n. ${ }^{\circ}$ 4; RAP 532].

Ciccotti 1891: 3 y 12; Etienne 1958: 200; Francisco Martín 1996: 125. Origo: quizás Pax Iulia, por el título flaminal.

Cursus: pont [ if ex], flam( en) Pacis Iuliae [-], flamen [ i perpetuus ? - ] ${ }^{75}$. Fecha: desconocida.

75 A pesar de que la deficiente transmisión del texto impide precisar su sentido correcto, parece que se trata de un homenaje hecho a un notable local, como se apunta en IRCP. Sorprende, sin embargo, la presencia de tres sacerdocios de rango local en su carrera, pues tal acumulación de funciones sacras no tiene paralelos en la provincia. La restitución que propone Curchin (fiam. Pacis Iuliae, [pont. (vel sac.) si [ve flami[ni oppidi incertiy), sacerdocios en más de una ciudad, no se atestigua entre los sacerdocios 
36. $[-]$

Sobreiral (Ninho de Açor, Castelo Branco).

Encarnação 1989=HEp 3, 1993, 468.1 [AE 1990, 492; Dias 1992: 467, n. $\left.{ }^{\circ} 157\right]$.

Origo: desconocida.

Título: [sa]cerdo $(s)$.

Contexto ritual: h[os]tiam ded[ic]avit.

Fecha: desconocida.

37. $[-]$

Bobadela (Oliveira do Hospital, Coimbra).

Rodrigues 1959-60: 127, n. ${ }^{\circ} 24$.

Origo: desconocida.

Título: flamen $[\text { ¿Div?- / ¿August?-Jorum [-] }]^{76}$.

Fecha: desconocida.

38. $[-]$

Ossonoba (Faro).

CIL II, 514177 [ILER 1514; IRCP 8; RAP 521].

Ciccotti 1891: 3; Etienne 1958: 200; Curchin 1990: n. ${ }^{\circ}$ 378; Francisco Martin 1996: 124.

Origo: quizás de Ossonoba, por el título duumviral. Curchin sugiere su condición de nativo de Vipasca, porque tras el cognomen aparece la expresión $V i[-e] n s i$.

Cursus: [fl]am[en et] Ilvir [OJssonob(ensi).

Fecha: la presencia de superlativos sugiere una fecha posterior al s. II (IRCP).

masculinos, y me parece poco probable. Si la lectura de los títulos que se sigue en IRCP fuera correcta, sería preferible restituir como sigue: pont[ifici] / flam(ini) Pacis Iuliae [-] / flami[ni perpetuo -7; la sucesión de sacerdocios culminaría, en esta interpretación, con el otorgamiento del título honorífico de la perpetuidad ( $c f$ Delgado Delgado 1998: 148 ss.).

76 El estado extremadamente fragmentario de la inscripción impide un desarrollo seguro del título. Los títulos flamen Divorum, flamen Divorum Augustorum y flamen Augustorum tienen paralelos en la provincia (n. ${ }^{\circ}$ 9, 19, 25, 39).

77 La restitución propuesta por Hübner es muy hipotética, como él mismo reconoce, ya que la realizó "ex imagine delineata accurate quidem, sed non perite, quam misit Soromenho". De ella lo que más seguro parece es la lectura del cursus del personaje que encabeza el epígrafe y que sigo aquí. En la actualidad se desconoce el paradero del epígrafe.

Conimbriga, 39 (2000) 107-152 
39. $[-]$

Faião (Terrugem, Sintra, Lisboa).

Ribeiro 1974/77: 288 ss. [AE 1979, 336; RAP 541].

Delgado Delgado 2000: apdo. 2.2.

Origo: desconocida.

Cursus: ¿[-II]v(ir)?, fla(men) Aug. [- $\mathbf{y}^{\mathbf{7 8}}$.

Fecha: "primeira metade do terceiro quartel do séc. I d. C.", según Ribeiro (por formulario - restos -, tipología del monumento y comparación con fechas de flámines de Olisipo).

Inscripciones de autenticidad dudosa:

\section{a) Iun(ia) Verecunda}

Monsaraz (Reguengos de Monsaraz, Évora).

CIL II, 115 y p. 805 [ILER 5673, p. 845; IRCP, p.443 B; RAP, p. 658 d].

Ciccotti 1891: 11; Etienne 1958: 239; Maxfield 1981: 248; Hoyo Calleja 1987: 193 s.; Stanley 1994; Mirón Pérez 1996: 333, n. ${ }^{\circ}$ 54; Francisco Martin 1996: 126.

Comentario: Th. Mommsen y E. Hiibner (ad CIL II; con ellos IRCP y RAP) tenían serias dudas sobre la autenticidad del epígrafe, sobre todo por el supuestamente singular cursus e insignias militares del hijo de la flaminica (VIviro iun. hast. leg. II Aug., torq. aur. et an. dupl. ob virt. donato). Stanley (tomando como base el trabajo de Maxfield) ha demostrado que las objeciones de estos autores y sus argumentos no son en absoluto concluyentes sobre su falsedad, ya que el cursus e insignias encajan bien en el contexto del siglo III. Igualmente duda de la capacidad de A. Resende para recrear un texto como este (como quería Hübner), especialmente por el nivel de conocimiento requerido sobre las insignias militares romanas. Téngase además en cuenta el comentario final de IRCP al epígrafe: "Note-se que, do ponto de vista paleográfico, está tudo praticamente impecável". Ciccotti, Etienne, Mirón Pérez o Francisco Martín, sin ningún comentario sobre su condición, incluyen la inscripción entre las auténticas; Hoyo Calleja, tras sintetizar las posiciones de Mommsen y Hübner, la considera autentica.

Origo: posiblemente Ebora, por el título flaminal.

Título: flam(inica) perp(etua) mun(icipii) Ebor(ensis).

Fecha: siglo III, por criterios prosopográficos (insignias militares del hijo de la flaminica, Maxfield).

b) [L.] Voconius L. f. Quir. Paullus

Ebora (Évora).

78 La inscripción está muy mutilada y lo único que se lee con cierta seguridad es el título flaminal.

Conirnbriga, 39 (2000) 107-152 
CIL II, 18*.

Birley 1953: 152, n. 34; Galsterer 1971: 56, n. 58; Devijver 1977: 880; Wiegels 1985: 77; Devijver 1987: 1779; Curchin 1990: 238, n. ${ }^{\circ} 20^{*}$; HEp 4, 1994, 1057.

Comentario: Para Hübner ( $a d$ CIL II) el texto es una falsificación probablemente del humanista $\mathrm{A}$. de Resende, de quien sospecha que pudo construir el formulario a través de CIL II, 4192 y 4201 (Tarraco); Curchin es de la misma opinión. Por contra, Birley, Galsterer, Alfoldy (apud Devijver), Devijver y Wiegels reivindican la autenticidad de la inscripción tomando como base principal la carrera del personaje, a la que consideran perfectamente aceptable. En mi opinión, los aspectos internos de la inscripción son lo suficientemente sospechosos como para plantear una duda razonable sobre su autenticidad. Aparte del paralelismo formular con los textos de Tarraco, Hübner también apuntó lo excepcional que resultaba la mención de la obtención del duovirado por sexta vez en el cursus del personaje. A todo ello debo añadir que el título flaminal resulta muy difícil de explicar en el contexto cultual de Lusitania, pues no existe ningún testimonio del culto de Roma (el título no tiene paralelos en la provincia); tal culto, por otra parte, está bien atestiguado en la Tarraconense (Alfoldy 1973: 46 ss.).

Origo: ¿Eboral.

Cursus: aed(ilis), q(uaestor), Ilvir VI, flam(en) Rom(ae) Divorum et Augg(ustorum), praef(ectus) coh(ortis) I Lusit(anorum) et coh(ortis) I Vettonum, (centurio) leg(ionis) III Ital(ica).

Fecha: no anterior a mediados del s. II, por el título flaminal (Galsterer).

c) $[-]$

Vila Nova da Baronia (Alvito, Beja).

IRCP, p. 300 [Almeida 1970; Encarnação 1971/75: passim। RAP, p. 568].

Hollo Calleja 1987: 197 ss.; Mirón Pérez 1996: 333.

Comentario: En IRCP (seguido por RAP) se considera este texto una falsificación renacentista, tanto por criterios externos (estado fragmentario y abundancia de nexos) como internos ("Visando localizar uma desconhecida civitas Mirietanorum, de importância bastante para ter flaminia, a epígrafe tem um sabor literário claramente renascentista: veja-se a frase pudicissima ac religiosissima temporis sui femina”). Almeida, sin embargo, aunque destaca que no es habitual el exceso de superlativos y de nexos, y se extraña de la presencia de una flaminica en un área donde han aparecida otras, cree en su autenticidad, pareciéndole que el tipo de letra es correcto. También Hoyo Calleja piensa que el texto es auténtico, e indica, acertadamente, que la presencia de más de una flaminica en una misma zona no debe ser motivo de extrañeza. Mirón Pérez, por su parte, la considera dudosa. En mi opinión, los 
argumentos planteados en IRCP siembran efectivamente dudas razonables sobre la autenticidad del texto. Sin embargo son infundadas las sospechas de IRPC y Almeida en lo referente al título flaminal, tanto porque el flaminado era un cargo anual y por tanto es normal que aparezcan varios testimonios en una misma ciudad, como porque este sacerdocio no fue exclusivo de colonias y municipios, pues se constata en ciudades no privilegiadas (ver Delgado Delgado 1998: esp. 85 ss. y 148s s.; id. 2001: passim). Por otra parte, el hecho de que la civitas Mirietanorum no sea mencionado por ninguna otra fuente, no es indicio necesariamente de falsedad.

Origo: desconocida (¿civitas Mirietanoruml).

Título: flam[inica] perpetua civitatis Mirietanorum.

Fecha: "final do império", por criterios paleográficos (Almeida).

\section{Bibliografía y abreviaturas epigráficas}

Las abreviaturas de las revistas se citan según L'Année Philologique.

Abascal (J.M.) 1994. Los nombres personales en las inscripciones latinas de Hispania, Murcia.

Abascal (J.M.) y Espinosa (U.) 1989. La ciudad hispanorromana, privilegio y poder, Logroño.

$\mathrm{AE}=$ L'Année Epigraphique.

ALFõLdy (G.) 1973. Flamines provinciae Hispaniae Citerioris, Madrid.

ALFõLdy (G.) 1987. Rõmisches Stadtewesen auf der neukastilischen Hochebene, Heidelberg.

Almeida (F. de) 1970. "Mais uma flaminica na Bacia do Sado", Revista de Guimarães 80, 377-380.

Alvar (J.) 1981. "EI culto de Mitra en Hispania", MHA 5, 51-72.

Alvar (J.) 1993. "Los cultos mistéricos en Lusitania", en Actas del II Congreso Peninsular de Historia Antigua, Coimbra, 789-814.

AMaral (A. E. Maia do) 1982. "Sobre três inscrições perdidas de Bobadela (Oliveira do Hospital)", Conimbriga 21, 106-126.

AnaCleto (R.) 1981. Bobadela Epigráfica, Coimbra.

BEND ALA Galán (M.) 1986. "Die orientalischen Religionen Hispaniens in vorrõmischer und rõmischer Zeit", A/V/?WII 18.1, 345-408.

BENVENISTE (E.) 1983 (ed. or. 1969). Vocabulario de las instituciones indoeuropeas, Madrid.

BEURLIER (E.) 1891. Le cuite impérial, son histoire et son organisation depuis Auguste jusqua Justinien, París.

Birley (E.) 1953 (reimp. 1961). Roman Britain and the Roman Army, Kendal.

BRANDão (D. de Pinho) 1972. "Epigrafia romana coliponense", Conimbriga 11, 41-192.

Cagnat (R.) 1914 (reimpr. 1976). Cours d'epigraphie latine, Paris.

CAMPBell (L.A.) 1968. Mithraic Iconography and Ideology, Leiden.

Conimbriga, 39 (2000) 107-152 
Castillo (C.) 1991. "El progreso de la epigrafía romana en Hispania (1983-1987)", Emerita 59(2), 225-273.

CiccoTTi (E.) 1891. "I sacerdozi municipali e provinciali della Spagna e gli Augustali neirépoca imperiale romana", RFIC 19, 1-84.

$\mathrm{CIL}=$ Corpus Inscriptionum Latinarum.

Clauss (M.) 1992. Cultores Mithrae. Die Anhangerschaft des Mithras-Kultes, Stuttgart.

Crespo OrTíz de ZÁrate (S.) 1997. "Sacerdotes y sacerdocio en las religiones indoeuropeas de Hispania prerromana y romana", 7lu 2, 17-37.

Cruz (M. D. Gimo da) 1986. "A propósito de uma inscrição honorífica do Museu de Santarém”, Arqueología 14, 115-121.

CurChIN (L.A.) 1982. "Notes and Corrections to the Latin Epigraphy of Spain", ZPE 47, 105-111.

CurChIN (L.A.) 1990. The Local Magistrates of the Roman Spain, Toronto.

Dardaine (S.) - Pavis d'Escurac (H.) 1986. "Ravitaillement des cités et évergétisme annonaire dans les provinces occidentales sous le Haut-Empire", Ktema 11, 291302.

Degrassi (A.) 1952. I fasti consolari delT impero romano dal 30 avanti Cristo al 613 dopo Cristo, Roma.

Deininger (J.) 1965. Die Provinziallandtage der Romischen Kaiserzeit von Augustus bis zum Ende des dritten Jahrhunderts $n$. Chr., Munich-Berlin.

Delgado Delgado (J.A.) 1998. Elites y organización de la religion en las provincias romanas de la Bética y las Mauritanias: sacerdotes y sacerdocios, Oxford (BAR S724).

Delgado Delgado (J.A.) 1999. “Flamines provinciae Lusitaniae”, Gerión 17, 433461.

Delgado Delgado (J.A.) 2000. "Los augures y el augurado en la Hispania romana: estudio sobre un sacerdocio de tradición romana en un ámbito provincial", Hispania Antiqua 24, en prensa.

Delgado Delgado (J.A.) 2000b. Sacerdocios y sacerdotes de la Antigüedad Clásica, Madrid, en prensa.

Delgado Delgado (J.A.) 2001. "Los fasti sacerdotum de las ciudades de la Bética", Habis 32, en prensa.

Demougin (S.) 1992. Prosopographie des chevaliers romains julio-claudiens, Roma.

Dias (M. M. Alves) 1981. "Os cultos orientais em Pax Mia, Lusitânia”, MHA 5, 33-39.

DiAS (M. M. Alves) 1992. "Para um repertorio das inscrições romanas do territorio portugués (1989)", Euphrosyne 20, 467-472.

DesJardins (E.) 1879. "Le culte des divi et le cuite de Rome et d'Auguste", RPh 3, 33-63.

DESSAU (H.) 1892-1916. Inscriptiones Latinae Selectae, Berlín.

DeviJver (H.) 1976. Pro sopo graphia militiarum equestrium quae fuerunt ab Augusto ad Gallienum. I, Lovaina.

DeviJVer (H.) 1977. Prosopographia militiarum equestrium quae fuerunt ab Augusto ad Gallienum. II, Lovaina.

DeviJver (H.) 1987. Prosopographia militiarum equestrium quae fuerunt ab Augusto ad Gallienum. Supplementum I, Lovaina. 
Duthoy (R.) 1969. The Taurobolium. IPs Evolution and Terminology, Leiden.

Edmondson (J. C.) 1984. "Mithras at Pax Iulia - a reexamination", Conimbriga 23, 72-86.

Edmondson (J. C.) 1997. “Two Dedications to Divus Augustus and Diva Augusta from Augusta Emerita and the Early Development of the Imperial Cult in Lusitania Re-Examined", MM 38, 89-105.

$\mathrm{EE}=$ Ephemeris Epigraphica.

ENCARNAÇÃo (J. d') 1971/75. "Autenticidade em Epigrafia - as inscrições de Cuba e de Vila Nova da Baronia", $A B$ 28/32, 57-62.

ENCARNAÇÃo (J. d') 1981. "A religião romana não-oficial nas colónias e municípios da Lusitânia durante o Alto Império", MHA 5, 19-31.

EnCarnaÇão (J. d') 1984. Inscrições Romanas do Conventus Pacensis, Coimbra.

EnCARNaÇão (J. d') 1989. "Inscrição votiva de Ninho de Açor", Ficheiro Epigráfico $33, n .^{\circ} 150$.

$\mathrm{ERAE}=($ ver García Iglesias, $\mathrm{L})$.

ETIEnNe (R.) 1958. Le culte impérial dans la Péninsule Ibérique d Auguste à Dioclétien, Paris.

FARIA (J. C. Lázaro) 1984. "Dois fragmentos de placas de Alcácer do Sal (Conventus Pacensis)", Ficheiro Epigráfico 9, 14-16.

FISHWICK (D.) 1970. "On CIL 2, 473”, AJPh 91, 79-82.

FishwicK (D.) 1987. The Imperial Cult in the Latin West. Studies in the Ruler Cult of the Western Provinces of the Roman Empire. Vol. 1,1-1,2, Leiden.

FISKE (G. C.) 1900. "Notes on the Worship of the Roman Emperors in Spain", HSPh $11,101-139$.

FITA (F.) 1882. "Inscripciones romanas de la ciudad y partido de Talavera (provincia de Toledo)", BRAH 2, 248-302.

Francisco Casado (M.A. de) 1989. El culto de Mithra en Hispania, Granada.

FranCisCo Martín (J. de) 19962. Conquista y romanización de Lusitania, Salamanca.

GALSTERER (H.) 1971. Untersuchungen zum rómischen Stadtewesen auf der Iberischen Halbinsel, Berlín.

GarCia (J. M.) 1984. Epigrafía lusitano-romana do Museu Tavares Proença Júnior, Castelo Branco.

GarCia (J. M.) 1991. Religiões antigas de Portugal. Fontes epigráficas, Lisboa.

GARCÍA Y Bellido (A.) 1949. Esculturas romanas de España y Portugal, Madrid.

GARCíA Y BELLIDo (A.) 1967. Les religions orientales dans la Péninsule Ibérique, Leiden.

GARCía IgLeSIAS (L.) 1972. Epigrafia romana de Augusta Emérita, Madrid (tesis doctoral inédita).

García Quíntela (M.V.) 1999. Mitología y mitos de la Hispania Prerromana, III, Madrid.

GEIGER (F.) 1913. De sacerdotibus Augustorum municipalibus, Halle.

$\mathrm{HAE}=$ Hispania Antiqua Epigraphica .

$\mathrm{HEp}=$ Hispania Epigraphica .

HIRSCHFELd (O.) 1866. "I sacerdozi dei municipi romani nell' Africa", Annali delVInstituto di Correspondeza Archeologica 38, 28-77.

Conimbriga, 39 (2000) 107-152 
Herbst (H.) 1883. De sacerdotiis Romanorum municipalibus. Quaestio epigraphica, Halle.

Hoyo Calleja (J. del) 1987. La importancia de la mujer hispanorromana en la Tarraconense y Lusitania a la luz de los documentos epigráficos. Aspectos religiosos y socioeconómicos, Madrid.

ILER $=($ ver Vives, J.).

ILS $=($ ver Dessau, H.).

IRCP = (ver Encarnação, J. d' 1984).

JULLIAN (C.) 1896. "Flamen, Flaminica, Flamonium", DS 11,2, 1156-1188.

KLEMENTA (S.) 1993. Gelagerte Flufigótter des Spathellenismus und der rómischen Kaiserzeit, Colonia.

KorNEMANN (E.) 1901. "Zur Geschichte der antiken Herrscherkulte”, Klio 1, 51-146.

KRASCHENINNIKOFF (M.) 1894. "Über die Einführung des provinzialen Kaisercultus im rómischen Westen”, Philologus 53, 147-189.

LAD AGE (D.) 1971. Stadtische Priester- und Kultamter im Lateinischen Westen des Imperium Romanum zur Kaiserzeit, Colonia.

LAMBRINO (S.) 1951. "Inscriptions latines du Musée Leite de Vasconcelos", O Archeologo Portugués (n.s.) 1, 37-61.

LAMbrino (S.) 1953. "Les divinités orientales en Lusitanie et le sanctuaire de Panóias", Bulletin des études portugaises 17, 93-129.

LAMBrino (S.) 1954. Les divinités orientales en Lusitanie et le sanctuaire de Panóias, Coimbra.

LATTE (K.) 1960. Rómische Religions geschichte, Munich.

LE RouX (P.) 1972. "Recherches sur les centurions de la Legio VII Gemina", MCV 8, 89-147.

Mantas (V. Gil da Cruz Soares) 1976. "Notas acerca de três inscrições de Olisipo", Conimbriga 15, 151-169.

Marco Simón (F.) 1994. "La religión indígena en la Hispania indoeuropea", en Historia de las religiones de la Europa antigua, Madrid, 313-400.

MARQUARDT (J.) 18852 (reimp. 1975). Rómische Staatsverwaltung III. Das Sacralwesen, Leipzig.

MaXfield (V. A.) 1981. The Military Decorations of the Roman Army, Berkeley.

MelChOR GIL (E.) 1993/94. "Las élites municipales de Hispania en el alto imperio: un intento de aproximación a sus fuentes de riqueza", Florentia Iliberritana 4-5, 335-348.

MÉLIDA (J. R.) 1925. Catálogo monumental de España. Badajoz, Madrid.

Menella (G.) 1989. "I prefetti municipali degli imperatori e del Cesar nella Spagna romana", en Actas del Congreso Internacional de Epigrafía Jurídica, Pamplona, 377-389.

MerKelbaCh (R.) 1984. Mithras, Meisenheim - Konigstein.

Mirón PÉREz (M. D.) 1996. Mujeres, religión y poder: el culto imperial en el occidente mediterráneo, Granada.

ProsPer (B.) 1994. "El teónimo paleohispano Trebarune", Veleia 11, 187-195.

Conimbriga, 39 (2000) 107-152 
Ramírez Sádaba (J.L.) 1993. "Panorámica religiosa de Augusta Emerita", en Religio Deorum. Actas del coloquio internacional de epigrafía Culto y Sociedad en Occidente, Sabadell, 389-398.

RAP $=($ ver Garcia, J. M. 1991).

Ribeiro (J.) 1976. "Duas inscrições inéditas do Museu de Castelo Branco", Conimbriga $15,135-138$.

RIBEIRo (J. Cardim) 1974/77. "Três novos monumentos epigráficos da época romana pertencentes à zona oeste do município olisiponense", $A P$ 7-9, 288-302.

RIBEIRO (J. Cardim) 1982/83. "Estudos históricos-epigráficos em tomo da figura de $L$. Iulius Maelo Caudicus", Sintria 1-2, 151-476.

Rodrigues (M. L.) 1959-60. "Inscrições romanas do Museu Machado de Castro", Humanitas 11-12 (=n.s. 8-9), 112-132.

RodrígueZ NeILA (J. F.) 1981. "Magistraturas municipales y funciones religiosas en la Hispania romana", Revista de estudios de la vida local 209, 91-118.

SCHILLINGER (K.) 1979. Untersuchungen zur Entwicklung des Magna Mater-Kultes im Westen des Kaiserreiches, diss. Konstanz.

STANLEY (F. H.) 1994. "CIF II 115: Observations on the only Sevir Iunior in Roman Spain”, ZPE 102, 226-236.

Thomas (G.) 1982. "Magna Mater and Attis", $A N R W$ II, 17.3, 1500-1535.

Tout AIN (J.) 1907. Les cuites pai'ens dans V Empire Romain. Les provinces latines. I. Les cuites officiels; les cuites romains et gréco-romains, París.

Trillmich (W.) 1993. "<Foro provincial und $<$ Foro municipal in den Hauptstádten der drei hispanischen Provinzen: eine Fiktion", en Ciudad y comunidad cívica en Hispania. Siglos IIy III d.C., Madrid, 115-124.

TurCaN (R.) 1992. Les cuites orientaux dans le monde romain, París.

VASCONCELOS (J. Feite de) 1895. "Excursão archeologica a Alcácer do Sal”, O Archeologo Português 1, 65-92.

VAsConcelos (J. Leite de) 1913. Religiões da Lusitânia. Vol. ///, Lisboa.

VAsconcelos (J. Leite de) 1927-29. "Epigrafia do Museu Etnológico (Belem). Inscrições romanas", O Archeologo Portugués 28, 209-227.

VASCONCELOS (J. Leite de) 1935. “A mãe dos deuses", Brotéria 20, 255-257.

VERMASEREN (M. J.) 1956. Corpus inscriptionum et monumentorum religionis Mithriacae. /., La Haya.

Vermaseren (M. J.) 1986. Corpus Cultus Cybelae Attidisque.V. Aegyptus, Africa, Hispania, Gallia et Britannia, Leiden.

Viana (A.) 1952. "Epigrafia Pacense: As pedras de Cenáculo", $A B$ 9, 3-17.

VIEIRA (A.) 1944. Epigrafia de Olisipo, Lisboa.

VIVES (J.) 1971-72. Inscripciones latinas de la España Romana, Barcelona.

WeSCh-KLEIN (G.) 1993. Funus Publicum, Stuttgart.

WiEGELS (R.) 1985. Die Tribusinschriften des rõmischen Hispanien: ein Katalog, Berlin.

Wissowa (G.) 19122 (reimp. 1971). Religion und Kultus der Rõmer, Munich. 